\title{
1,3-Dibromo-1,1-difluoro-2-propanone as a Useful Synthon for a Chemoselective Preparation of 4-Bromodifluoromethyl Thiazoles
}

\author{
Marco Colella, ${ }^{\dagger}$ Pantaleo Musci, ${ }^{\dagger}$ Claudia Carlucci, ${ }^{\dagger}$ Samuele Lillini, ${ }^{\S}$ Mara Tomassetti,

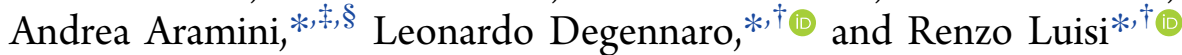 \\ ${ }^{\dagger}$ Department of Pharmacy-Drug Sciences, University of Bari “A. Moro” Via E. Orabona 4, Bari 70125, Italy \\ ${ }^{\ddagger}$ Department of Discovery, Dompé Farmaceutici S.p.A., Via Campo di Pile, L’Aquila 67100, Italy \\ ${ }^{\S}$ Department of Discovery, Dompé Farmaceutici S.p.A., Via Pietro Castellino, Napoli 80131, Italy
}

Supporting Information

\begin{abstract}
We report herein a synthetic protocol for the preparation of 1,3-dibromo-1,1-difluoro-2-propanone, a new synthon used for the first time in a reaction with aromatic amines and sodium thiocyanate, leading to thiazoles which are useful candidates in drug discovery programs. The new synthon allows to introduce a bromodifluoromethyl group at

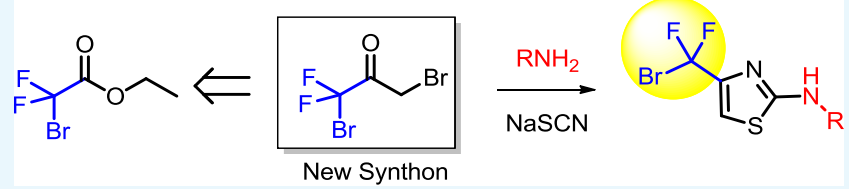
the $\mathrm{C} 4$ of the thiazole, and it is amenable of further transformation such as the $\mathrm{Br} / \mathrm{F}$ exchange useful in radiopharmaceutics. Application of the strategy to the preparation of a precursor of the biologically relevant DF2755Y is also reported.
\end{abstract}

\section{INTRODUCTION}

The increased presence of fluorine in pharmaceuticals ${ }^{1}$ and agrochemicals, ${ }^{2}$ as well as in material sciences, ${ }^{3}$ continues to stimulate research interests in the development of methodologies for the preparation of fluorine-containing compounds. ${ }^{4}$ Among the several approaches for the introduction of a fluorinated moiety into organic molecules, methods for trifluoro- and difluoromethylation as well as difluoromethylenation have been widely provided in recent years. ${ }^{5}$ In contrast, methods for the introduction of halodifluoromethyl units $\left(-\mathrm{CF}_{2} \mathrm{X}\right)$ have received less attention. Thus, convenient strategies for introducing $-\mathrm{CF}_{2} \mathrm{X}$ groups are still in demand because halodifluoromethylated compounds are useful synthetic intermediates ${ }^{6}$ for the preparation of biologically relevant compounds, as the difluoromethylene unit is considered isosteric and isopolar to an ethereal oxygen. ${ }^{7}$ In addition, iodo, bromo, and chlorodifluoromethylated aromatics and heteroaromatics are recognized as potential candidates for undergoing the halogen/fluorine exchange processes, ${ }^{8}$ and thus potential valuable precursors of $\left[{ }^{18} \mathrm{~F}\right]$ trifluoromethylated compounds for positron emission tomography imaging. ${ }^{9}$ Moreover, because of the relatively short half-life $(110 \mathrm{~min})$ of the ${ }^{18} \mathrm{~F}$ radioisotope, the (hetero)aryl $\mathrm{CF}_{2}-\left[{ }^{18} \mathrm{~F}\right]$ bond construction is often required as the late-stage synthetic step. ${ }^{10}$ In this context, we became interested in the chemistry of fluorinated 2-aminothiazoles as structural elements screened in our drug discovery programs. ${ }^{11}$ In particular, our recent efforts focused on (2S)-2-(4-\{[4-(trifluoromethyl)-1,3-thiazol-2-yl]amino\}phenyl)propanoic acid (DF2755Y) (Scheme 1), a small molecule belonging to a novel allosteric dual CXCR1/ CXCR2 inhibitor with a favorable oral pharmacokinetic profile. This molecule selectively inhibited neutrophil chemotaxis induced by CXCR1/2 ligands without affecting on CXCL8
Scheme 1

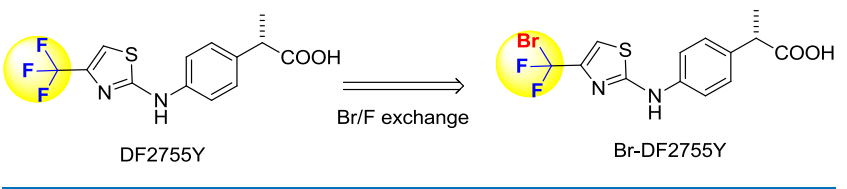

binding to these receptors. The activation of CXCR $1 / 2$ has been implicated in the genesis of inflammatory and postoperative pain and progression of severe chronic diseases, including rheumatoid arthritis, chronic obstructive pulmonary disease, Alzheimer's disease, melanoma, and several urological diseases. ${ }^{12}$ Furthermore, the results might suggest that this small molecule can be a candidate for a novel therapeutic option to control inflammatory and postoperative pain. ${ }^{3}$

Given the importance in drug discovery of this promising molecule and other fluorinated aminothiazoles in the pipeline, we embarked in a project aimed at developing 4-bromodifluoromethyl aminothiazole scaffolds as potential precursors of $\left[{ }^{18} \mathrm{~F}\right]$-radiotracers by a late-stage $\mathrm{Br} / \mathrm{F}$ exchange reaction.

On the basis of these premises, we noticed that the main strategies available for introducing the $\mathrm{CF}_{2} \mathrm{Br}$ group into (hetero)aromatic rings rely on: (a) a direct incorporation of the bromodifluoromethyl group as a ${ }^{+} \mathrm{CF}_{2} \mathrm{Br}$ equivalent in the presence of arylmetal species (Scheme $2 \mathrm{a}),{ }^{14}$ (b) a direct radical bromodifluoromethylation of heteroaromatics (i.e. benzofurans or benzo[b]thiophene) using the $\mathrm{BrCF}_{2} \mathrm{SO}_{2} \mathrm{Na}$ reagent (Scheme $2 \mathrm{~b}),{ }^{15}$ and (c) a bromination with $\mathrm{N}$ bromosuccinimide (NBS) or $\mathrm{Br}_{2}$ of fluorine-containing compounds (Scheme 2c). ${ }^{16}$ However, each strategy has

Received: September 4, 2018

Accepted: October 22, 2018

Published: November 5, 2018 
Scheme 2. Strategies $(a-c)$ for the Construction of Bromodifluoromethylated Scaffolds

a)

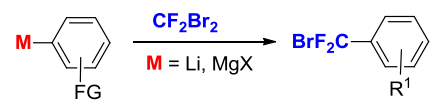

b)

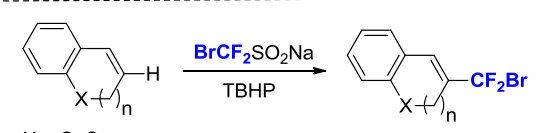

$\mathrm{X}=\mathrm{O}, \mathrm{s}$

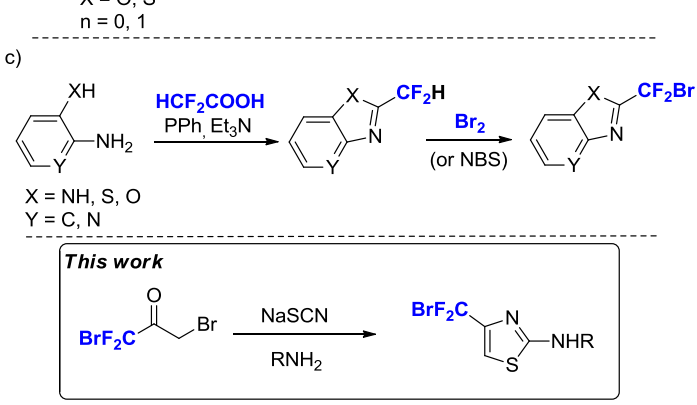

synthetic limitations, whereas complementary ways to $\mathrm{CF}_{2} \mathrm{Br}$ containing building blocks are quite rare and reported the use of $\mathrm{BrCF}_{2} \mathrm{CO}_{2} \mathrm{Et}$ or the corresponding carboxylic acid as $\mathrm{CF}_{2} \mathrm{Br}$ containing building blocks for the synthesis of $2-\mathrm{CF}_{2} \mathrm{Br}$ substituted 1,3-imidazolines, 1,3-oxazolines, 1,3-benzoxazole, and 5-( $\left.\mathrm{CF}_{2} \mathrm{Br}\right)-1,2,4$-oxadiazoles for pharmaceutical scopes. ${ }^{17}$ We reasoned that the use of a new $\mathrm{CF}_{2} \mathrm{Br}$-containing reagent could have been an alternative strategy to construct other $\mathrm{CF}_{2} \mathrm{Br}$-substituted heterocycles.

Various methodologies, such as Hantzsch and CookHeilbron, have been reported for the synthesis of aminothiazole and their derivatives. The Hantzsch thiazole synthesis, one of the widest used methodology, involves the reaction of $\alpha$-halo carbonyl compounds with thiourea or thioamides. ${ }^{18}$ To the best our knowledge, there are no reported examples on the use of the Hantzsch-type approach for the preparation of 4$\mathrm{CF}_{2} \mathrm{Br}$-substituted 2-aminothiazoles, whereas it is reported an isolate example of direct C-5 bromodifluoromethylation of 2trifluoroacetamido-4-(trifluoromethyl)thiazole by treatment with $n$-BuLi and $\mathrm{CF}_{2} \mathrm{Br}_{2}$ at low temperature. ${ }^{19}$

Thereby, we envisioned that a 1,3-dihalo-1,1-difluoro-2propanone could be an attractive building block to provide straightforward access to $4-\mathrm{CF}_{2} \mathrm{Br}$-substituted 2-aminothiazoles, by reaction with aromatic amines and sodium thiocyanate. ${ }^{20}$ With our surprise, we were unable to find precedence about the synthesis of this type of synthon (Scheme 2).

\section{RESULTS AND DISCUSSION}

We started our investigation by exploring different synthetic pathways for obtaining the desired synthon 3 (Scheme 3). First, with the aim to introduce by a one-pot procedure two bromine atoms at 1,3-positions of commercially available 1,1difluoropropanone, the commonly reported halogenation protocol with $\mathrm{Br}_{2}$ or NBS was considered. In principle, the double bromination of this substrate, on both $\mathrm{sp}^{3}$ carbons, could have directly provided us the desired product. However, monitoring this reaction in a NMR tube using $\mathrm{Br}_{2}$, catalytic $\mathrm{AcOH}$, and $\mathrm{CDCl}_{3}$ as solvent, only mono bromination occurred with high selectivity at C-3, giving bromoketone 2 in good yield, whereas the $\mathrm{CF}_{2} \mathrm{H}$ group resulted insensitive to
Scheme 3. Alternative Approaches (a,b) for the Synthesis of Synthon 3

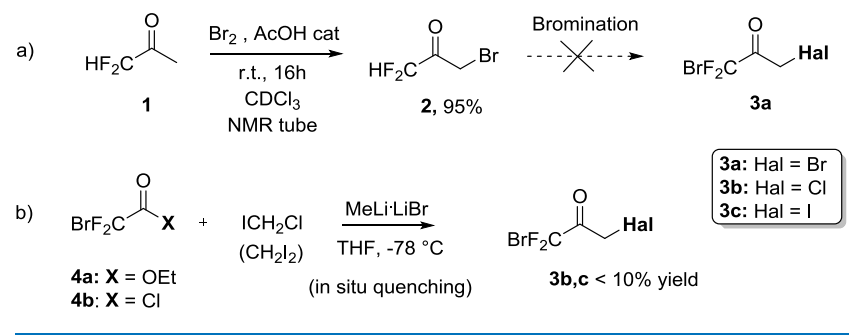

bromine. All attempts, using $\mathrm{Br}_{2}$ or NBS in the presence of acid or AIBN, to introduce a second bromine atom at C-1 failed. With these lines of evidence in hand, we explored a different strategy, evaluating the possibility of a direct introduction of the halomethyl moiety by nucleophilic addition of a metalated halomethyl group on a readily available difluoromethyl acetate $\mathbf{4 a}$ or the corresponding acylchloride $\mathbf{4 b}$ (Scheme $3 \mathrm{~b}$ ). Very recently, we developed an efficient flow method for the direct halomethylation of several electrophiles by trapping of halomethyllithium intermediates generated from haloiodomethanes. $^{21}$ Thus, we explored the reactivity of lithium carbenoids, derived from $\mathrm{ICH}_{2} \mathrm{Cl}$ and $\mathrm{I}_{2} \mathrm{CH}_{2}$, with commercial ester $\mathbf{4 a}$ and acyl chloride $\mathbf{4 b}$ exhibiting the $\mathrm{CF}_{2} \mathrm{Br}$ group. Under optimized reaction conditions, using $\mathrm{MeLi} \cdot \mathrm{LiBr}$ as a lithiating agent and 1:1 diethyl ether/tetrahydrofuran (THF) mixture as a solvent, at $-78{ }^{\circ} \mathrm{C}$ under internal quenching conditions, ${ }^{1} \mathrm{H}$ NMR and $\mathrm{GC}-\mathrm{MS}$ analysis (Scheme $3 \mathrm{~b}$ ) revealed the formation of a complex mixture, and all attempts to isolate the detected products $3 \mathbf{b}$ and $3 \mathbf{c}$ failed.

After these unsatisfactory results, a different approach was evaluated, and based on the preliminary introduction of a methyl group into ester $\mathbf{4 a}$, leading to ketone $\mathbf{5}$, followed by a subsequent bromination step, as reported in Scheme 4. Thus,

Scheme 4. Two-Step Synthesis of Synthon 3

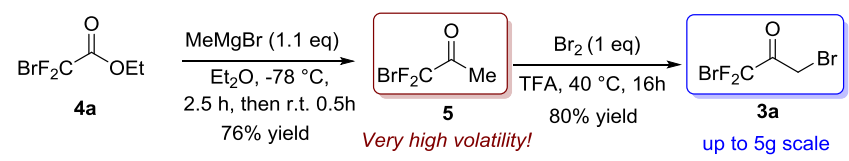

according to a reported protocol, we attempted the reaction of the commercially available ethyl 1-bromo-1,1-difluoroethanoate $\mathbf{4 a}$ with methylmagnesium bromide, in diethyl ether at $-78{ }^{\circ} \mathrm{C}$. After ${ }^{1} \mathrm{H},{ }^{19} \mathrm{~F}$, and ${ }^{13} \mathrm{C}$ NMR analysis, we were pleased to confirm the presence of the expected ketone 5 (76\% yield). Unfortunately, the high volatility of the product did not allow the complete removal of diethyl ether solvent. Therefore, the ethereal solution of $\mathbf{5}$, titrated by ${ }^{1} \mathrm{H}$ NMR using mesitylene as the internal standard, was directly used for the following step.

The subsequent bromination step afforded $3 a$ in $80 \%$ yield (Scheme 4). The best reaction conditions for bromination used trifluoroacetic acid (TFA) as a solvent and heated at 40 ${ }^{\circ} \mathrm{C}$ for $16 \mathrm{~h}$. To reduce the formation of polyhalogenated side products, $\mathrm{Br}_{2}$ was added in portions, whereas reaction evolution was monitored by ${ }^{1} \mathrm{H}$ - and ${ }^{19} \mathrm{~F}$ NMR. Under these conditions, the conversion of $\mathbf{5}$ was complete and the ketone 3 a was isolated in high purity by distillation ( $>90 \%$ by NMR). This halogenated ketone resulted sensitive to air and moisture, thus requiring inert atmosphere conditions, amber container, and because of its volatility, it is recommended for lowtemperature $\left(4^{\circ} \mathrm{C}\right)$ storage. 
Scheme 5. Scope of the Reaction

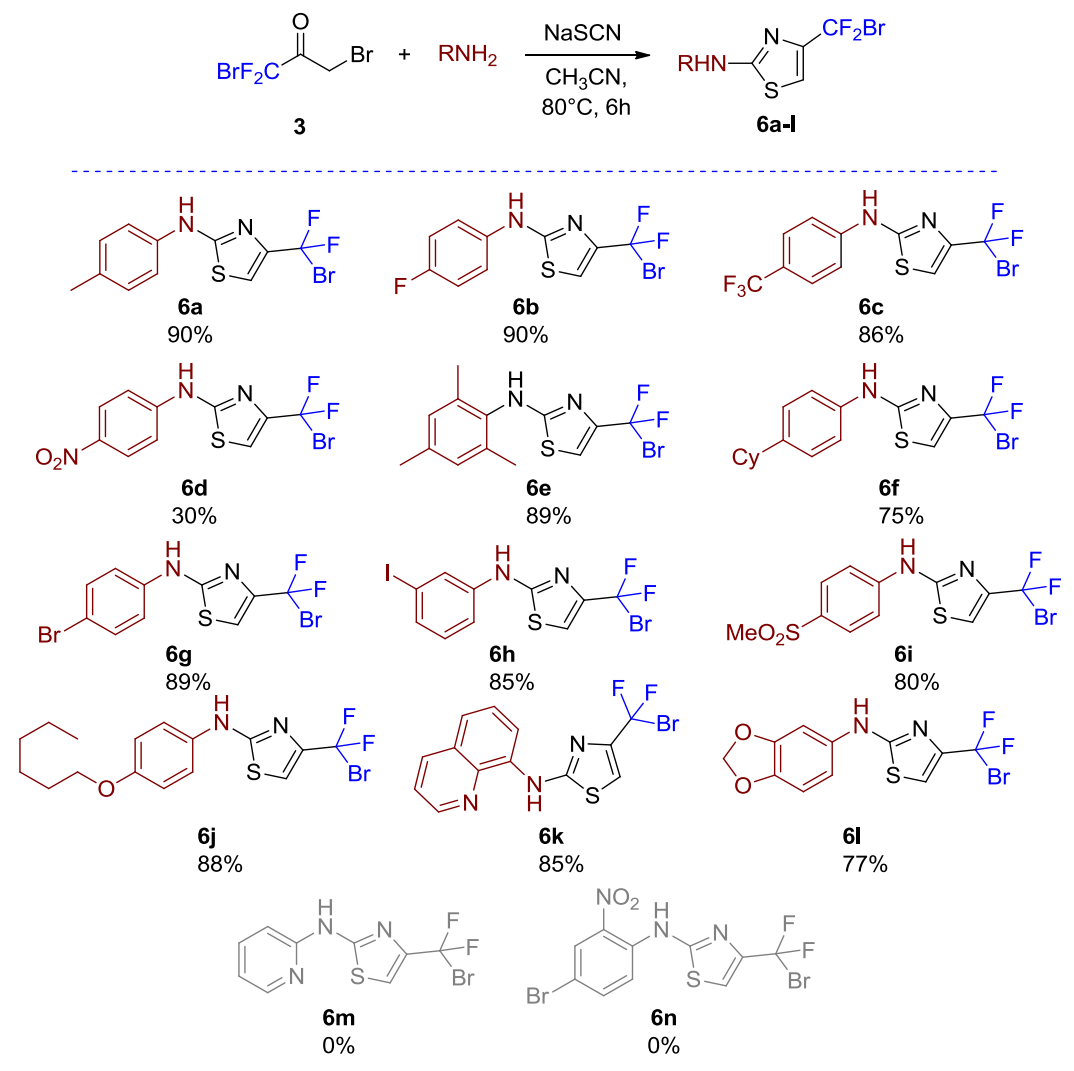

With this new synthon in hand, the synthesis of 4bromodifluoromethyl-thiazoles $(6 \mathbf{a}-\mathbf{l})$ was directly carried out by condensation of ketone $3 \mathbf{a}$ with several aromatic amines and in the presence of sodium thiocyanate (Scheme 5)..$^{22}$ As reported in Scheme 4 , the reaction worked well with several aromatic amines being tolerant to different substituents on the aromatic ring. The presence of a strong electronwithdrawing group as in the case of the $p$-nitroaniline provided low yield of the corresponding thiazole $6 \mathbf{d}$. In striking contrast, the reaction was not significantly affected by the presence of fluoro, trifluoromethyl, and methylsulfonyl groups, affording derivatives $\mathbf{6 b}, \mathbf{6 c}$, and $\mathbf{6 i}$ in good yields. The presence on the aromatic ring of electron-donating substituents was also tolerated, leading to derivatives $\mathbf{6 j}$ and $\mathbf{6} \mathbf{1}$ in high yields. Unfortunately, the expected thiazoles $6 \mathrm{~m}$ and $6 \mathrm{n}$ were not observed using 2-aminopyridine and 4-bromo-2-nitroaniline, likely because of an electronic effect that could decrease the nucleophilicity of the amine nitrogen.

With the aim to further validate the importance of this kind of functionalized bromodifluoromethylated thiazoles, we investigated the possibility to setup a fast and reproducible halogen/fluorine-exchange protocol. In particular, we were keen to demonstrate that the bromine atom could be replaced by the fluorine atom, using a fluoride anion as nucleophile, and in a reasonable time, compatible with ${ }^{18} \mathrm{~F}$-fluorination platforms. In fact, the use of anionic nucleophilic fluorination is preferred over electrophilic fluorination because of the higher specific activity after radiolabeling. ${ }^{23}$ Derivatives $6 \mathbf{a}$ and 6j were used as test compounds and subjected to reaction under "cold" conditions using KF as the source of fluoride ions, kryptofix 222 as the cryptand for potassium cation, and AgOTf as the promoter in acetonitrile at room temperature (Scheme 6).
Scheme 6. Applications of Halogen/Fluorine Exchange

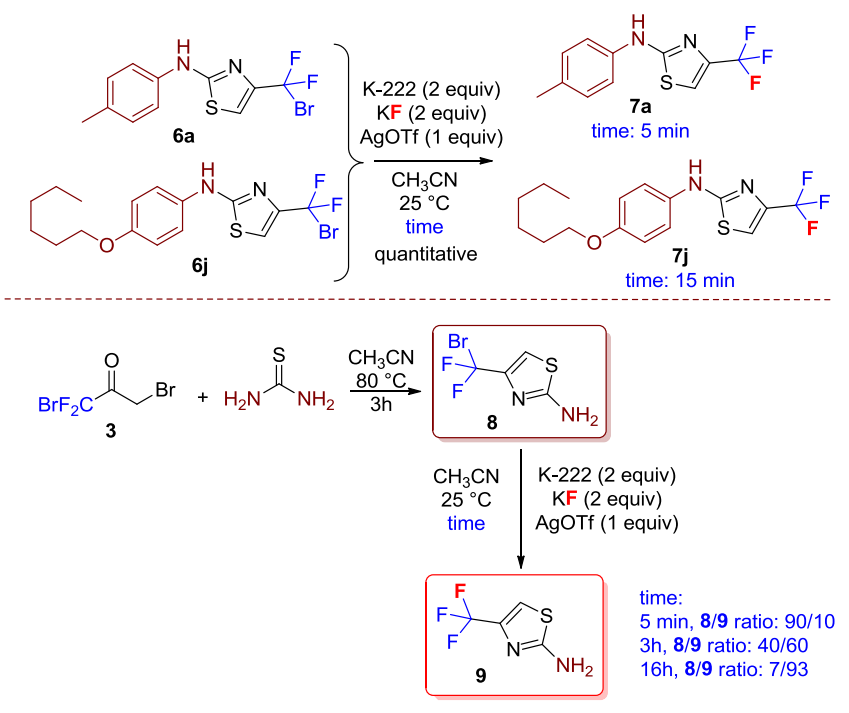

As reported in Scheme 6, the reaction performed very well providing the exchange products $7 \mathbf{a}$ and $7 \mathbf{j}$ quantitatively in only 5-15 min, as demonstrated by ${ }^{19} \mathrm{~F}$ NMR monitoring (see Supporting Information). Nicely, the observed short reaction time for complete $\mathrm{Br} / \mathrm{F}$ exchange could potentially be useful for a late-stage ${ }^{18} \mathrm{~F}$ radiolabeling experiment. Next, the preparation of 2 -aminothiazole $\mathbf{8}$ was also pursued using synthon $3 \mathrm{a}$ in the presence of thiourea, obtaining thiazole 8 in almost quantitative yield. Exchange protocol on thiazole 8 provided the 2-amino-4-trifluoromethylthiazole 9, a valuable building block in medicinal chemistry; however, at $25{ }^{\circ} \mathrm{C}$, a variable degree of fluorine incorporation was observed, 
Scheme 7. Applications of the Strategy to DF2755Y

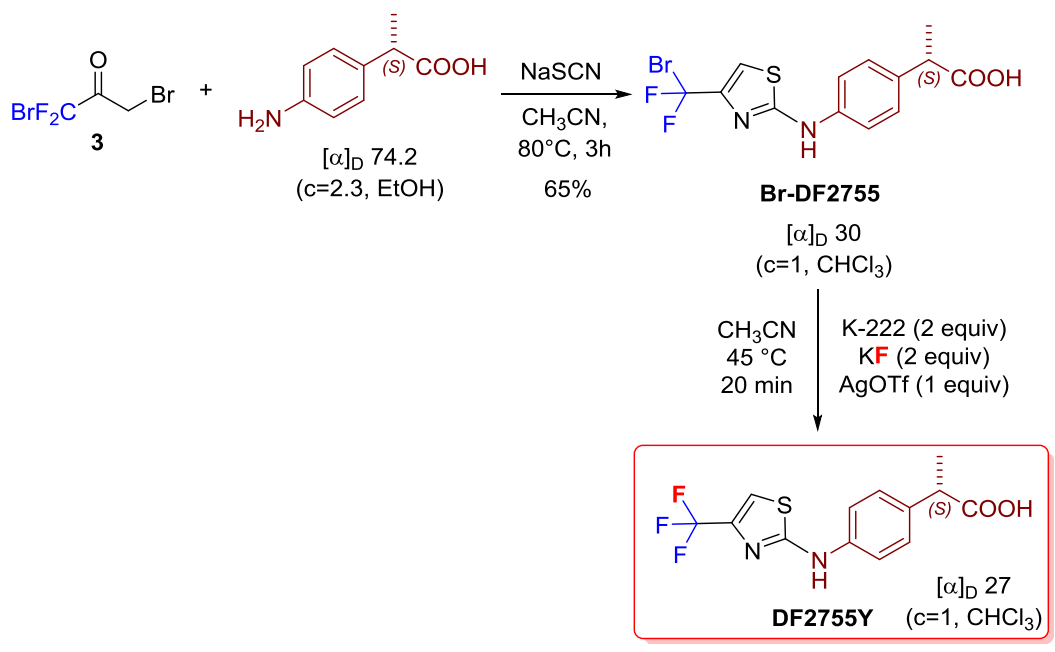

depending on the reaction time (Scheme 6). To further prove the usefulness of this approach, the synthon 3a was tested for the preparation of Br-DF2755, a precursor of the drug candidate DF2755Y. As reported in Scheme 7, reacting 3a with chiral $(S)$-p-aminophenylacetic acid in the presence of sodiumthiocyanate led to the target compound Br-DF2755 in good yield (Scheme 7). With the precursor Br-DF2755 in our hands, we investigated the possibility of $\mathrm{Br} / \mathrm{F}$ exchange under optimized conditions. We were glad to observe a complete exchange in $20 \mathrm{~min}$ by using the optimized conditions adopted for $\mathbf{6 a}$ and $\mathbf{6 j}$ (Scheme 6) in terms of reagents stoichiometry but running the reaction at $80{ }^{\circ} \mathrm{C}$. This represents a remarkable result for us because it opens the possibility either to develop a radiotracer for DF2755Y or to investigate the drug distribution in vivo.

\section{CONCLUSIONS}

In conclusion, we reported, for the first time, a new synthetic strategy for the synthesis of $4-\mathrm{CF}_{2} \mathrm{Br}$-substituted 2-aminothiazoles based on the use of the 1,3-dibromo-1,1-difluoro-2propanone as a useful synthon. The usefulness of this reagent has been demonstrated in preparation of several 4-bromodifluoromethyl thiazoles which are precursors for a $\mathrm{Br} / \mathrm{F}$ exchange reaction. The strategy has been applied to the preparation of Br-DF2755, precursor of the biologically relevant DF2755Y. Further studies ongoing in our laboratories are aimed at preparing ${ }^{18} \mathrm{~F}$-labeled derivatives and at expanding the developed methodology. Results will be reported in due course.

\section{EXPERIMENTAL SECTION}

General (Standard Techniques). The chemicals (compounds 1, 2, 4a, and $4 \mathbf{b}$ ) and solvents were purchased from TCI Europe, Fluorochem, VWR, Aldrich Chemical Company, and used without purification except $\mathrm{Et}_{2} \mathrm{O}$ and THF which were distilled over $\mathrm{Na}$ /benzophenone prior to use. Melting points were measured with Büchi melting point B-545. ${ }^{1} \mathrm{H}$ $\mathrm{NMR},{ }^{13} \mathrm{C}$ NMR, and ${ }^{18} \mathrm{~F}$ NMR spectra were recorded using Bruker 700, Agilent 300 and $500 \mathrm{MHz}$. $\mathrm{CDCl}_{3}, \mathrm{CD}_{3} \mathrm{OD}$ were used as solvents. Data are expressed as follows: chemical shift [multiplicity, coupling constant in $\mathrm{Hz}$, integration]. Infrared spectra of the compounds were recorded by using a PerkinElmer 283 spectrometer or by using attenuated total reflection spectrophotometer in reciprocal centimeter. ESI-MS analyses performed on Agilent 110 LC/MSD mass spectrometer with ionic single quadrupole trap system and Exalibur data system. TLC was carried out on a $0.25 \mathrm{~mm}$ precoated silica gel thick plates (Merck) with a fluorescence indicator F-254; compounds were detected either under UV light (at $254 \mathrm{~nm}$ ) or by spraying with sulfuric acid or permanganate solution. Silica gel 70-230 mesh and 230-400 mesh were used for flash chromatography on glass columns.

Procedure for the Preparation of 1,3-Dibromo-1,1difluoropropan-2-one (3a). According to the reported procedure, ${ }^{8}$ to a solution of ethyl 2-bromo-2,2-difluoroacetate $(10 \mathrm{~g}, 49.3 \mathrm{mmol})$ in dry diethyl ether $(54 \mathrm{~mL})$ at $-78{ }^{\circ} \mathrm{C}$, methyl magnesiumbromide ( $3 \mathrm{M}$ solution in diethyl ether, 18 $\mathrm{mL}$ ) was added dropwise, and the mixture was stirred at -78 ${ }^{\circ} \mathrm{C}$ for $2.5 \mathrm{~h}$ and an additional $30 \mathrm{~min}$ at room temperature. The reaction was quenched with water $(5 \mathrm{~mL})$, and the organic phase was dried over sodium sulfate. The ethereal solution was filtrated and concentrated under moderate vacuum (600-700 Torr) until $30 \mathrm{~mL}$ of final volume because of the high volatility of the product. The concentration of 1bromo-1,1-difluoropropan-2-one $\left(5^{1}\right)$ was evaluated by $\mathrm{H}$ NMR analysis using mesitylene as the internal standard $(1.25 \mathrm{M}), 76 \%$ yield. ${ }^{1} \mathrm{H}$ NMR (500 MHz, $\mathrm{CDCl}_{3}$ ): $\delta 2.46$ (s, $3 \mathrm{H}) .{ }^{13} \mathrm{C} \mathrm{NMR}\left(126 \mathrm{MHz}, \mathrm{CDCl}_{3}\right): \delta 189.4(\mathrm{t}, J=27.3 \mathrm{~Hz}$, $\mathrm{C}=\mathrm{O}), 113.9\left(\mathrm{t},{ }^{1} \mathrm{~J}_{(\mathrm{C}-\mathrm{F})}=319.2 \mathrm{~Hz}, \mathrm{CF}_{2} \mathrm{Br}\right), 22.3\left(\mathrm{CH}_{3}\right) \cdot{ }^{19} \mathrm{~F}$ NMR (282 MHz, $\left.\mathrm{CDCl}_{3}\right): \delta-65.6(2 \mathrm{~F})$. To a titrated ethereal solution of 1-bromo-1,1-difluoropropan-2-one (6) (6.4 g, 37.4 mmol), TFA $(980 \mu \mathrm{L}, 12.8 \mathrm{mmol})$ was added dropwise. To this solution, $\mathrm{Br}_{2}(1.9 \mathrm{~mL}, 37.4 \mathrm{mmol})$ was added in portions (200 $\mu \mathrm{L}$ each) while monitoring the progress of the reaction by ${ }^{1} \mathrm{H}$ - and ${ }^{19} \mathrm{~F}$ NMR. The mixture was heated at $40{ }^{\circ} \mathrm{C}$ and stirred for $16 \mathrm{~h}$. The reaction was quenched with aqueous solution of sodium metabisulfite $(0.1 \mathrm{M}, 100 \mu \mathrm{L})$. The crude was diluted with dichloromethane $(15 \mathrm{~mL})$ and washed with water $(3 \times 5 \mathrm{~mL})$. The organic phase was dried over sodium sulfate and the solvent was removed under reduced pressure. The obtained brown oil was purified by bulb to bulb distillation $\left(50{ }^{\circ} \mathrm{C}, 10^{-2}\right.$ Torr $)$, affording the 1,3-dibromo1,1-difluoropropan-2-one (3a) as a colorless oil (4.7 g, 18.7 $\mathrm{mmol}$ ), $80 \%$ yield. IR (film) $/ \mathrm{cm}^{-1}: 2921,2086,1642 .{ }^{1} \mathrm{H}$ NMR (500 MHz, $\left.\mathrm{CDCl}_{3}\right): \delta 4.35(\mathrm{~s}, 2 \mathrm{H}) \cdot{ }^{13} \mathrm{C}$ NMR $(126$ $\left.\mathrm{MHz}, \mathrm{CDCl}_{3}\right): \delta 183.7\left(\mathrm{t},{ }^{2} J_{(\mathrm{C}-\mathrm{F})}=27.8 \mathrm{~Hz}, \mathrm{C}=\mathrm{O}\right), 112.0(\mathrm{t}$, 
$\left.{ }^{1} J_{(\mathrm{C}-\mathrm{F})}=319.7 \mathrm{~Hz}, \mathrm{CF}_{2} \mathrm{Br}\right), 26.2\left(\mathrm{~s}, \mathrm{CH}_{2} \mathrm{Br}\right) \cdot{ }^{19} \mathrm{~F}$ NMR $(470$ $\mathrm{MHz}, \mathrm{CDCl}_{3}$ ): $\delta-62.9(2 \mathrm{~F})$. HRMS (ESI-TOF) $\mathrm{m} / z$ : calcd for $\mathrm{C}_{3} \mathrm{H}_{1} \mathrm{Br}_{2} \mathrm{~F}_{2} \mathrm{O}[\mathrm{M}-\mathrm{H}]^{-}$, 250.8342; found, 250.8332 .

General Procedure for the Preparation of Thiazole $(6 a-1)$. A solution of 1,3-dibromo-1,1-difluoropropan-2-one (3a) $(98 \mathrm{mg}, 0.39 \mathrm{mmol})$ and sodium thiocyanate $(31 \mathrm{mg}$, $0.39 \mathrm{mmol})$ in dry acetonitrile $(500 \mu \mathrm{L})$ in a sealed tube was stirred at ambient temperature for $15 \mathrm{~min}$. Subsequently, $p$ toluidine $(41 \mathrm{mg}, 0.39 \mathrm{mmol}$ ) was added dropwise, and the mixture was heated to $80{ }^{\circ} \mathrm{C}$ for $3 \mathrm{~h}$ in an oil bath. After this time, the mixture was taken up with $5 \mathrm{~mL}$ of AcOEt and filtered on celite pad. The solvent was removed under reduced pressure, and the crude was purified by flash chromatography on silica gel to afford the desired product.

[4-(Bromodifluoromethyl)-1,3-thiazol-2-yl](p-tolyl)amine (6a). (111 mg, 90\%). $R_{\mathrm{f}} 0.6$ (30\% EtOAc/n-hexane). $\mathrm{mp} 114-$ $116^{\circ} \mathrm{C} .{ }^{1} \mathrm{H}$ NMR $\left(700 \mathrm{MHz}, \mathrm{CDCl}_{3}\right): \delta 7.33$ (br s, $\left.1 \mathrm{H}, \mathrm{NH}\right)$, 7.21-7.19 (m, 4H, $4 \times$ Ar-H), $6.90(\mathrm{~s}, 1 \mathrm{H}$, HetAr-H), $2.35(\mathrm{~s}$, $\left.3 \mathrm{H}, \mathrm{CH}_{3}\right) \cdot{ }^{13} \mathrm{C}$ NMR $\left(176 \mathrm{MHz}, \mathrm{CDCl}_{3}\right): \delta 167.3(\mathrm{C}=\mathrm{N})$, $146.8\left(\mathrm{t},{ }^{2} J_{(\mathrm{C}-\mathrm{F})}=28.6 \mathrm{~Hz}, \mathrm{Ar}-\mathrm{Cq}\right), 137.0(\mathrm{Ar}-\mathrm{Cq}), 134.8(\mathrm{Ar}-$ $\mathrm{Cq}), 130.4(2 \times \operatorname{Ar}-\mathrm{C}), 120.3(2 \times \operatorname{Ar}-\mathrm{C}), 114.2\left(\mathrm{t},{ }^{1} J_{(\mathrm{C}-\mathrm{F})}=\right.$ $\left.302.0 \mathrm{~Hz}, \mathrm{CF}_{2} \mathrm{Br}\right), 106.5\left(\mathrm{t},{ }^{3} J_{(\mathrm{C}-\mathrm{F})}=5.1 \mathrm{~Hz}, \mathrm{Ar}-\mathrm{C}\right), 21.0$ $\left(\mathrm{CH}_{3}\right) .{ }^{19} \mathrm{~F}$ NMR $\left(470 \mathrm{MHz}, \mathrm{CDCl}_{3}\right): \delta-46.5(2 \mathrm{~F}) . \mathrm{IR}$ (film) $/ \mathrm{cm}^{-1}: 3188,3085,2957,1591,1575,1514,1353,1191$, $1119,1069,966,794$. HRMS (ESI-TOF) $\mathrm{m} / z$ : calcd for $\mathrm{C}_{11} \mathrm{H}_{10} \mathrm{BrF}_{2} \mathrm{~N}_{2} \mathrm{~S}[\mathrm{M}+\mathrm{H}]^{+}$, 318.9716; found, 318.9712.

[4-(Bromodifluoromethyl)-1,3-thiazol-2-yl] ( $p$ fluorophenyl)amine (6b). Orange oil (113 mg, 90\%). $R_{\mathrm{f}} 0.6$ (30\% EtOAc/n-hexane). ${ }^{1} \mathrm{H}$ NMR (700 $\left.\mathrm{MHz}, \mathrm{CDCl}_{3}\right): 7.67$ (br s, $1 \mathrm{H}, \mathrm{NH}), 7.34$ (dd, $J=8.6,4.5 \mathrm{~Hz}, 2 \mathrm{H}, 2 \times \mathrm{Ar}-\mathrm{H}), 7.10$ $\left(\mathrm{t}, J=8.6 \mathrm{~Hz}, 2 \mathrm{H}, 2 \times\right.$ Ar-H), $6.91\left(\mathrm{~s}, 1 \mathrm{H}\right.$, HetAr-H). ${ }^{13} \mathrm{C}$ $\operatorname{NMR}\left(176 \mathrm{MHz}, \mathrm{CDCl}_{3}\right): \delta 167.8(\mathrm{C}=\mathrm{N}), 160.1\left(\mathrm{~d},{ }^{1} J_{(\mathrm{C}-\mathrm{F})}\right.$ $=244.9 \mathrm{~Hz}, \mathrm{Ar}-\mathrm{Cq}), 146.0\left(\mathrm{t},{ }^{2} J_{(\mathrm{C}-\mathrm{F})}=28.5 \mathrm{~Hz}, \mathrm{Ar}-\mathrm{Cq}\right), 135.8$ $\left(\mathrm{d},{ }^{4} J_{(\mathrm{C}-\mathrm{F})}=3.0 \mathrm{~Hz}, \mathrm{Ar}-\mathrm{Cq}\right), 123.0\left(\mathrm{~d},{ }^{3} J_{(\mathrm{C}-\mathrm{F})}=8.2 \mathrm{~Hz}, 2 \times \mathrm{Ar}-\right.$ C), $116.7\left(\mathrm{~d},{ }^{2} J_{(\mathrm{C}-\mathrm{F})}=22.8 \mathrm{~Hz}, 2 \times \mathrm{Ar}-\mathrm{C}\right), 114.0\left(\mathrm{t},{ }^{1} J_{(\mathrm{C}-\mathrm{F})}=\right.$ $\left.300.0 \mathrm{~Hz}, \mathrm{CF}_{2} \mathrm{Br}\right), 106.7\left(\mathrm{t},{ }^{3} J_{(\mathrm{C}-\mathrm{F})}=4.7 \mathrm{~Hz}, \mathrm{Ar}-\mathrm{C}\right) .{ }^{19} \mathrm{~F}$ NMR $\left(470 \mathrm{MHz}, \mathrm{CDCl}_{3}\right): \delta-46.6(2 \mathrm{~F}),-117.1$ (1F). IR (film)/ $\mathrm{cm}^{-1}: 3148,2919,1581,1509,1440,1212,1197,1133,1078$, 966,802, 734. HRMS (ESI-TOF) $\mathrm{m} / z$ : calcd for $\mathrm{C}_{10} \mathrm{H}_{7} \mathrm{BrF}_{3} \mathrm{~N}_{2} \mathrm{~S}[\mathrm{M}+\mathrm{H}]^{+}$, 322.9465; found, 322.9451 .

[4-(Bromodifluoromethyl)-1,3-thiazol-2-yl][p-(1,1,1trifluoromethyl)phenyl]amine (6c). Orange oil (125 mg, 86\%). Rf 0.6 (30\% EtOAc/ $n$-hexane). ${ }^{1} \mathrm{H}$ NMR (700 MHz, $\left.\mathrm{CDCl}_{3}\right): \delta 7.64(\mathrm{~d}, J=8.4 \mathrm{~Hz}, 2 \mathrm{H}, \mathrm{Ar}-\mathrm{H}), 7.59(\mathrm{br} \mathrm{s}, 1 \mathrm{H}$, $\mathrm{NH}), 7.49(\mathrm{~d}, J=8.4 \mathrm{~Hz}, 2 \mathrm{H}, \operatorname{Ar}-\mathrm{H}), 7.06(\mathrm{~s}, 1 \mathrm{H}$, HetAr-H). ${ }^{13} \mathrm{C}$ NMR $(176 \mathrm{MHz}, \mathrm{CDCl} 3): \delta 164.2(\mathrm{C}=\mathrm{N}), 146.9(\mathrm{t}$, $\left.{ }^{2} J_{(\mathrm{C}-\mathrm{F})}=29.3 \mathrm{~Hz}, \mathrm{Ar}-\mathrm{Cq}\right), 142.4(\mathrm{Ar}-\mathrm{Cq}), 127.1\left(\mathrm{t},{ }^{3} J_{(\mathrm{C}-\mathrm{F})}=\right.$ $3.7 \mathrm{~Hz}, \mathrm{Ar}-\mathrm{C}), 125.5\left(\mathrm{q},{ }^{2} J_{(\mathrm{C}-\mathrm{F})}=33.1 \mathrm{~Hz}, \mathrm{Ar}-\mathrm{Cq}\right), 124.2(\mathrm{q}$, $\left.{ }^{1} J_{(\mathrm{C}-\mathrm{F})}=271.8 \mathrm{~Hz}, \mathrm{CF}_{3}\right), 117.7(2 \times \mathrm{Ar}-\mathrm{C}), 113.9\left(\mathrm{t},{ }^{1} J_{(\mathrm{C}-\mathrm{F})}=\right.$ $\left.300.1 \mathrm{~Hz}, \mathrm{CF}_{2} \mathrm{Br}\right), 107.9\left(\mathrm{q},{ }^{3} J_{(\mathrm{C}-\mathrm{F})}=4.6 \mathrm{~Hz}, 2 \times \mathrm{Ar}-\mathrm{C}\right) .{ }^{19} \mathrm{~F}$ NMR $\left(282 \mathrm{MHz}, \mathrm{CDCl}_{3}\right): \delta-46.7(2 \mathrm{~F}),-62.0(3 \mathrm{~F})$. IR (film) $/ \mathrm{cm}^{-1}: 3293,2918,2850,1617,1535,1442,1416,1325$, 1191, 1116, 1067, 968. HRMS (ESI-TOF) $\mathrm{m} / \mathrm{z}$ : calcd for $\mathrm{C}_{11} \mathrm{H}_{5} \mathrm{BrF}_{5} \mathrm{~N}_{2} \mathrm{~S}[\mathrm{M}-\mathrm{H}]^{-}$, 370.9277; found, 370.9283 .

[4-(Bromodifluoromethyl)-1,3-thiazol-2-yl][pnitrophenyl]amine (6d). Orange oil (41 $\mathrm{mg}, 30 \%)$. Rf 0.6 (30\% EtOAc/n-hexane). ${ }^{1} \mathrm{H}$ NMR $\left(700 \mathrm{MHz}, \mathrm{CDCl}_{3}\right): \delta 8.28$ $(\mathrm{d}, J=9.0 \mathrm{~Hz}, 2 \mathrm{H}, 2 \times \mathrm{Ar}-\mathrm{H}), 7.64(\mathrm{br} \mathrm{s}, 1 \mathrm{H}, \mathrm{NH}), 7.58(\mathrm{~d}, J$ $=9.0 \mathrm{~Hz}, 2 \mathrm{H}, 2 \times \mathrm{Ar}-\mathrm{H}), 7.15(\mathrm{~s}, 1 \mathrm{H}$, HetAr-H$) \cdot{ }^{13} \mathrm{C} \mathrm{NMR}$ $\left(176 \mathrm{MHz}, \mathrm{CDCl}_{3}\right): \delta 162.7(\mathrm{C}=\mathrm{N}), 147.3\left(\mathrm{t},{ }^{2} J_{(\mathrm{C}-\mathrm{F})}=29.1\right.$ $\mathrm{Hz}, \mathrm{Ar}-\mathrm{Cq}), 144.9$ (Ar-Cq), 142.8 (Ar-Cq), 125.9 ( $2 \times \mathrm{Ar}-\mathrm{C})$, $116.8(2 \times \mathrm{Ar}-\mathrm{C}), 113.8\left(\mathrm{t},{ }^{1} J_{(\mathrm{C}-\mathrm{F})}=300.1 \mathrm{~Hz}, \mathrm{CF}_{2} \mathrm{Br}\right), 109.1$ $\left(\mathrm{t},{ }^{3} \mathrm{~J}_{(\mathrm{C}-\mathrm{F})}=4.6 \mathrm{~Hz}, \mathrm{Ar}-\mathrm{C}\right) \cdot{ }^{19} \mathrm{~F}$ NMR $(470 \mathrm{MHz} \mathrm{CDCl} 3): \delta$ -46.9 (2F). IR (film) $/ \mathrm{cm}^{-1}: 3325,2923,2852,1598,1526$, 1328, 1307, 1259, 1194, 1114, 1072, 968. HRMS (ESI-TOF) $m / z$ : calcd for $\mathrm{C}_{10} \mathrm{H}_{5} \mathrm{BrF}_{2} \mathrm{~N}_{3} \mathrm{O}_{2} \mathrm{~S}[\mathrm{M}-\mathrm{H}]^{-}$, 347.9254; found, 347.9258.

[4-(Bromodifluoromethyl)-1,3-thiazol-2-yl][1,3,5trimethylphenyl]amine (6e). Orange solid $(120 \mathrm{mg}, 89 \%) . R_{\mathrm{f}}$ 0.6 (30\% EtOAc/ $n$-hexane). mp $153-155{ }^{\circ} \mathrm{C} .{ }^{1} \mathrm{H}$ NMR (700 $\left.\mathrm{MHz}, \mathrm{CDCl}_{3}\right): \delta 7.83(\mathrm{br} \mathrm{s}, 1 \mathrm{H}, \mathrm{NH}), 6.97(\mathrm{~s}, 2 \mathrm{H}, 2 \times \mathrm{Ar}-\mathrm{H})$, $6.74(\mathrm{~s}, 1 \mathrm{H}, \mathrm{HetAr}-\mathrm{H}), 2.32\left(\mathrm{~s}, 3 \mathrm{H}, \mathrm{CH}_{3}\right), 2.27(\mathrm{~s}, 6 \mathrm{H}, 2 \times$ $\left.\mathrm{CH}_{3}\right) \cdot{ }^{13} \mathrm{C}$ NMR $\left(176 \mathrm{MHz}, \mathrm{CDCl}_{3}\right): \delta 172.2(\mathrm{C}=\mathrm{N}), 146.9$ $\left(\mathrm{t},{ }^{2} J_{(\mathrm{C}-\mathrm{F})}=28.2 \mathrm{~Hz}, \mathrm{Ar}-\mathrm{Cq}\right), 138.6(\mathrm{Ar}-\mathrm{Cq}), 136.9(2 \times \mathrm{Ar}-$ $\mathrm{Cq}), 134.4(\mathrm{Ar}-\mathrm{Cq}), 129.9(2 \times \mathrm{Ar}-\mathrm{C}), 114.2\left(\mathrm{t},{ }^{1} J_{(\mathrm{C}-\mathrm{F})}=\right.$ $\left.300.3 \mathrm{~Hz}, \mathrm{CF}_{2} \mathrm{Br}\right), 106.2\left(\mathrm{t},{ }^{3} J_{(\mathrm{C}-\mathrm{F})}=4.9 \mathrm{~Hz}, \mathrm{Ar}-\mathrm{C}\right), 21.2$ $\left(\mathrm{CH}_{3}\right), 18.1\left(2 \times \mathrm{CH}_{3}\right) \cdot{ }^{19} \mathrm{~F}$ NMR $\left(282 \mathrm{MHz}, \mathrm{CDCl}_{3}\right): \delta$ -46.2 (2F). IR (film) $/ \mathrm{cm}^{-1}: 3175,2921,2858,1610,1574$, 1428, 1353, 1192, 1123, 1072, 966, 800. HRMS (ESI-TOF) $m / z$ : calcd for $\mathrm{C}_{13} \mathrm{H}_{14} \mathrm{BrF}_{2} \mathrm{~N}_{2} \mathrm{~S}[\mathrm{M}+\mathrm{H}]^{+}$, 347.0029; found, 347.0025 .

[4-(Bromodifluoromethyl)-1,3-thiazol-2-yl]cyclohexylamine (6f). Orange oil (113 mg, 75\%). $R_{\mathrm{f}} 0.6(30 \%$ EtOAc/n-hexane). ${ }^{1} \mathrm{H}$ NMR $\left(700 \mathrm{MHz}, \mathrm{CDCl}_{3}\right): 7.34$ (br s, $1 \mathrm{H}, \mathrm{NH}), 7.23$ (s, 4H, Ar-H), 6.90 (s, 1H, HetAr-H) 2.52$2.48(\mathrm{~m}, 1 \mathrm{H}$, cyclohexyl), 1.92-1.82 (m, 4H, cyclohexyl), 1.78-1.74 (m, 1H, cyclohexyl), 1.44-1.37 (m, 4H, cyclohexyl), $1.28-1.24\left(\mathrm{~m}, 1 \mathrm{H}\right.$, cyclohexyl). ${ }^{13} \mathrm{C}$ NMR $(176 \mathrm{MHz}$, $\left.\mathrm{CDCl}_{3}\right): \delta 167.1(\mathrm{C}=\mathrm{N}), 146.9\left(\mathrm{t},{ }^{2} \mathrm{~J}_{(\mathrm{C}-\mathrm{F})}=28.5 \mathrm{~Hz}, \mathrm{Ar}-\mathrm{Cq}\right)$, 144.9 (Ar-Cq), $137.3(\mathrm{Ar}-\mathrm{Cq}) 128.2(2 \times \mathrm{Ar}-\mathrm{C}), 120.0(2 \times$ $\mathrm{Ar}-\mathrm{C}), 114.3\left(\mathrm{t},{ }^{1} J_{(\mathrm{C}-\mathrm{F})}=299.9 \mathrm{~Hz}, \mathrm{CF}_{2} \mathrm{Br}\right) 106.5\left(\mathrm{t},{ }^{3} J_{(\mathrm{C}-\mathrm{F})}=\right.$ 4.7, Ar-C), $44.2\left(\mathrm{Ph}-\mathrm{CH}\left(\mathrm{CH}_{2}\right)_{2}\right), 34.7\left(2 \times \mathrm{CH}_{2}\right), 27.0(2 \times$ $\left.\mathrm{CH}_{2}\right), 26.3\left(\mathrm{CH}_{2}\right) .{ }^{19} \mathrm{~F}$ NMR $\left(282 \mathrm{MHz}, \mathrm{CDCl}_{3}\right): \delta-46.5$ (2F). IR (film) $/ \mathrm{cm}^{-1}: 3245,2924,2851,1600,1548,1515$, 1447, 1194, 1121, 1071, 966, 797. HRMS (ESI-TOF) $\mathrm{m} / z$ : calcd for $\mathrm{C}_{16} \mathrm{H}_{18} \mathrm{BrF}_{2} \mathrm{~N}_{2} \mathrm{~S}[\mathrm{M}+\mathrm{H}]^{+}, 387.0342$; found, 387.0336.

[4-(Bromodifluoromethyl)-1,3-thiazol-2-yl] [4bromophenyl]amine (6g). Orange oil (133 mg, 89\%). Rf 0.6 (30\% EtOAc/ $n$-hexane). ${ }^{1} \mathrm{H}$ NMR $\left(700 \mathrm{MHz}, \mathrm{CDCl}_{3}\right): \delta 7.49$ $(\mathrm{d}, J=8.8 \mathrm{~Hz}, 2 \mathrm{H}, \mathrm{Ar}-\mathrm{H}), 7.27$ (d, $J=8.8 \mathrm{~Hz}, 2 \mathrm{H}, \mathrm{Ar}-\mathrm{H}), 6.97$ (s, 1H, HetAr-H). ${ }^{13} \mathrm{C}$ NMR $\left(176 \mathrm{MHz}, \mathrm{CDCl}_{3}\right): \delta 165.8$ $(\mathrm{C}=\mathrm{N}), 146.6\left(\mathrm{t},{ }^{2} J_{(\mathrm{C}-\mathrm{F})}=28.8 \mathrm{~Hz}, \mathrm{Ar}-\mathrm{Cq}\right), 138.6(\mathrm{Ar}-\mathrm{Cq})$, $132.8(2 \times \mathrm{Ar}-\mathrm{C}), 120.8(2 \times \mathrm{Ar}-\mathrm{C}), 116.9(\mathrm{Ar}-\mathrm{Cq}), 113.8(\mathrm{t}$, $\left.{ }^{1} J_{(\mathrm{C}-\mathrm{F})}=300.1 \mathrm{~Hz}, \mathrm{CF}_{2} \mathrm{Br}\right), 107.1\left(\mathrm{t},{ }^{3} J_{(\mathrm{C}-\mathrm{F})}=4.6 \mathrm{~Hz}, \mathrm{Ar}-\mathrm{C}\right)$. ${ }^{19} \mathrm{~F}$ NMR $\left(282 \mathrm{MHz}, \mathrm{CDCl}_{3}\right): \delta-46.7$ (2F). IR (film) $/ \mathrm{cm}^{-1}$ : 3292, 3122, 2924, 1674, 1592, 1545, 1489, 1308, 1193, 1125, 1072, 967. HRMS (ESI-TOF) $m / z$ : calcd for $\mathrm{C}_{10} \mathrm{H}_{7} \mathrm{Br}_{2} \mathrm{~F}_{2} \mathrm{~N}_{2} \mathrm{~S}$ $[\mathrm{M}+\mathrm{H}]^{+}, 384.8644$; found, 384.8631 .

[4-(Bromodifluoromethyl)-1,3-thiazol-2-yl][3iodophenyl]amine (6h). Orange oil (142 mg, 85\%). $R_{\mathrm{f}} 0.6$ (30\% EtOAc/ $n$-hexane). ${ }^{1} \mathrm{H}$ NMR $\left(500 \mathrm{MHz}, \mathrm{CDCl}_{3}\right): \delta 7.69$ $(\mathrm{t}, J=2.2 \mathrm{~Hz}, 1 \mathrm{H}, \mathrm{Ar}-\mathrm{H}), 7.46(\mathrm{~d}, J=8.0 \mathrm{~Hz}, 1 \mathrm{H}, \mathrm{Ar}-\mathrm{H}), 7.36$ (dd, $J=8.0,2.2 \mathrm{~Hz}, 1 \mathrm{H}, \mathrm{Ar}-\mathrm{H}), 7.11(\mathrm{t}, J=8.0 \mathrm{~Hz}, 1 \mathrm{H}, \mathrm{Ar}-\mathrm{H})$, $7.00(\mathrm{~s}, 1 \mathrm{H}, \mathrm{HetAr}-\mathrm{H}) .{ }^{13} \mathrm{C}$ NMR $\left(176 \mathrm{MHz}, \mathrm{CDCl}_{3}\right): \delta 165.1$ $(\mathrm{C}=\mathrm{N}), 147.0\left(\mathrm{t},{ }^{2} J_{(\mathrm{C}-\mathrm{F})}=30.9 \mathrm{~Hz}, \mathrm{Ar}-\mathrm{Cq}\right), 140.8(\mathrm{Ar}-\mathrm{Cq})$, 133.1 (Ar-C), 131.2 (Ar-C), 127.6 (Ar-C), 118.1 (Ar-C), $114.0\left(\mathrm{t},{ }^{1} J_{(\mathrm{C}-\mathrm{F})}=299.6 \mathrm{~Hz}, \mathrm{CF}_{2} \mathrm{Br}\right), 107.5\left(\mathrm{t},{ }^{3} J_{(\mathrm{C}-\mathrm{F})}=4.6 \mathrm{~Hz}\right.$, $\mathrm{Ar}-\mathrm{C}), 94.8$ (Ar-Cq). ${ }^{19} \mathrm{~F}$ NMR $\left(282 \mathrm{MHz}, \mathrm{CDCl}_{3}\right): \delta-46.7$ (s, 2F). IR (film) $/ \mathrm{cm}^{-1}: 3121,2922,2851,1587,1538,1474$, 1444, 1306, 1194, 1121, 1072, 967. HRMS (ESI-TOF) $\mathrm{m} / z$ : calcd for $\mathrm{C}_{10} \mathrm{H}_{7} \mathrm{BrF}_{2} \mathrm{IN}_{2} \mathrm{~S}[\mathrm{M}+\mathrm{H}]^{+}, 430.8526$; found, 430.8514.

[4-(Bromodifluoromethyl)-1,3-thiazol-2-yl][4methansolfonylphenyl]amine (6i). Brown oil (119 mg, 80\%). 
$R_{\mathrm{f}} 0.6$ (30\% $n$-hexane/EtOAc). ${ }^{1} \mathrm{H}$ NMR (700 MHz, acetone$\left.D_{6}\right): \delta 10.07$ (br s, $\left.1 \mathrm{H}, \mathrm{N}-\mathrm{H}\right), 7.97-7.92(\mathrm{~m}, 4 \mathrm{H}, \mathrm{Ar}-\mathrm{H}), 7.50$ (s, 1H, HetAr-H), $3.10\left(\mathrm{~s}, 3 \mathrm{H}, \mathrm{CH}_{3}\right) \cdot{ }^{13} \mathrm{C}$ NMR $(176 \mathrm{MHz}$, acetone- $\left.D_{6}\right): \delta 164.8(\mathrm{C}=\mathrm{N}), 147.1\left(\mathrm{t},{ }^{2} J_{(\mathrm{C}-\mathrm{F})}=28.5 \mathrm{~Hz}, \mathrm{Ar}-\right.$ Cq), 145.8 (Ar-Cq), 135.1 (Ar-Cq), $129.8(2 \times \mathrm{Ar}-\mathrm{C}), 118.0$ $(2 \times \operatorname{Ar}-\mathrm{C}), 115.3\left(\mathrm{t},{ }^{1} J_{(\mathrm{C}-\mathrm{F})}=298.2 \mathrm{~Hz}, \mathrm{CF}_{2} \mathrm{Br}\right), 110.6(\mathrm{t}$, $\left.{ }^{3} J_{(\mathrm{C}-\mathrm{F})}=4.8, \mathrm{Ar}-\mathrm{C}\right), 44.8\left(\mathrm{CH}_{3}\right) \cdot{ }^{19} \mathrm{~F}\left(470 \mathrm{MHz}\right.$, acetone- $\left.D_{6}\right)$ : $\delta-47.0$ (2F). IR (film) $/ \mathrm{cm}^{-1}: 3308,3123,2924,1596,1525$, 1410, 1322, 1294, 1196, 1141, 1092, 965. HRMS (ESI-TOF) $m / z$ : calcd for $\mathrm{C}_{11} \mathrm{H}_{8} \mathrm{BrF}_{2} \mathrm{~N}_{2} \mathrm{O}_{2} \mathrm{~S}_{2}[\mathrm{M}-\mathrm{H}]^{-}, 380.9179$; found, 380.9185 .

[4-(Bromodifluoromethyl)-1,3-thiazol-2-yl] [4hexyloxyphenyl]amine (6j). Orange oil (139 mg, 88\%). $R_{\mathrm{f}} 0.6$ (30\% EtOAc/ $n$-hexane). ${ }^{1} \mathrm{H}$ NMR (700 MHz, DMSO- $\left.D_{6}\right): \delta$ 10.33 (br s, $1 \mathrm{H}, \mathrm{NH}), 7.47$ (d, $J=9.1 \mathrm{~Hz}, 2 \mathrm{H}, \mathrm{Ar}-\mathrm{H}), 7.39$ (s, 1H, HetAr-H), 6.92 (d, $J=9.1 \mathrm{~Hz}, 2 \mathrm{H}, \mathrm{Ar}-\mathrm{H}), 3.92(\mathrm{t}, J=6.7$, $\left.2 \mathrm{H}, \mathrm{O}-\mathrm{CH}_{2}-\right), 1.71-1.65\left(\mathrm{~m}, 2 \mathrm{H}, \mathrm{CH}_{2}\right), 1.43-1.37(\mathrm{~m}, 2 \mathrm{H}$, $\left.\mathrm{CH}_{2}\right), 1.32-1.27\left(\mathrm{~m}, 4 \mathrm{H}, 2 \times \mathrm{CH}_{2}\right), 0.89-0.86\left(\mathrm{~m}, 3 \mathrm{H}, \mathrm{CH}_{3}\right)$. ${ }^{13} \mathrm{C}$ NMR (176 MHz, DMSO-D $): \delta 165.5(\mathrm{C}=\mathrm{N}), 154.3$ (Ar-Cq), $145.1\left(\mathrm{t},{ }^{2} J_{(\mathrm{C}-\mathrm{F})}=27.8 \mathrm{~Hz}, \mathrm{Ar}-\mathrm{Cq}\right), 133.8(\mathrm{Ar}-\mathrm{Cq})$, $119.5(2 \times \mathrm{Ar}-\mathrm{C}), 115.0(2 \times \mathrm{Ar}-\mathrm{C}), 114.5\left(\mathrm{t},{ }^{1} J_{(\mathrm{C}-\mathrm{F})}=298.0\right.$ $\left.\mathrm{Hz}, \mathrm{CF}_{2} \mathrm{Br}\right) 107.9\left(\mathrm{t},{ }^{3} \mathrm{~J}_{(\mathrm{C}-\mathrm{F})}=4.7, \mathrm{Ar}-\mathrm{C}\right), 67.7\left(\mathrm{O}-\mathrm{CH}_{2}\right), 31.1$ $\left(\mathrm{CH}_{2}\right), 28.8\left(\mathrm{CH}_{2}\right), 25.3\left(\mathrm{CH}_{2}\right), 22.2\left(\mathrm{CH}_{2}\right), 14.0\left(\mathrm{CH}_{3}\right) .{ }^{19} \mathrm{~F}$ NMR (470 MHz, DMSO- $\left.D_{6}\right): \delta-49.9(2 \mathrm{~F})$. IR (film) $/ \mathrm{cm}^{-1}$ : 3177, 2927, 2857, 1579, 1510, 1435, 1241, 1193, 1122, 1076, 965,793 . HRMS (ESI-TOF) $m / z$ : calcd for $\mathrm{C}_{16} \mathrm{H}_{18} \mathrm{BrF}_{2} \mathrm{~N}_{2} \mathrm{OS}$ $[\mathrm{M}-\mathrm{H}]^{-}$, 403.0291; found, 403.0288 .

8-[4-(Bromodifluoromethyl)-1,3-thiazol-2-ylamino]quinoline (6k). Orange oil (117 mg, 85\%). $R_{\mathrm{f}} 0.5(30 \%$ EtOAc/ $n$-hexane). ${ }^{1} \mathrm{H}$ NMR $\left(700 \mathrm{MHz}, \mathrm{CDCl}_{3}\right): \delta 9.97$ (br s, $1 \mathrm{H}, \mathrm{NH}), 8.82(\mathrm{~d}, J=4.1 \mathrm{~Hz}, 1 \mathrm{H}, \operatorname{Ar}-\mathrm{H}), 8.45(\mathrm{~d}, J=8.0 \mathrm{~Hz}$, $1 \mathrm{H}, \mathrm{Ar}-\mathrm{H}), 8.18$ (d, $J=8.2 \mathrm{~Hz}, 1 \mathrm{H}, \mathrm{Ar}-\mathrm{H}), 7.60(\mathrm{t}, J=8.2 \mathrm{~Hz}$, $1 \mathrm{H}, \mathrm{Ar}-\mathrm{H}), 7.48$ (dd, $J=8.0,4.1 \mathrm{~Hz}, 1 \mathrm{H}, \mathrm{Ar}-\mathrm{H}), 7.46(\mathrm{~d}, J=$ $8.2 \mathrm{~Hz}, 1 \mathrm{H}, \mathrm{Ar}-\mathrm{H}), 7.08$ (s, 1H, HetAr-H). ${ }^{13} \mathrm{C}$ NMR $(176$ $\left.\mathrm{MHz}, \mathrm{CDCl}_{3}\right): \delta 163.7(\mathrm{NH}-\mathrm{C}=\mathrm{N}), 148.1(\mathrm{Ar}-\mathrm{C}), 147.1(\mathrm{t}$, $\left.{ }^{3} J_{(\mathrm{C}-\mathrm{F})}=28.6 \mathrm{~Hz}, \mathrm{Ar}-\mathrm{Cq}\right), 137.9$ (Ar-Cq), 136.5 (Ar-C), 135.9 (Ar-Cq), 128.3 (Ar-Cq), 127.6 (Ar-C), 122.0 (Ar-C), 120.2 $(\mathrm{Ar}-\mathrm{C}), 114.3\left(\mathrm{t},{ }^{1} J_{(\mathrm{C}-\mathrm{F})}=300.3 \mathrm{~Hz}, \mathrm{CF}_{2} \mathrm{Br}\right), 113.0(\mathrm{Ar}-\mathrm{C})$, $107.6\left(\mathrm{t},{ }^{3} J_{(\mathrm{C}-\mathrm{F})}=4.6 \mathrm{~Hz}\right.$, Ar-C) $) .{ }^{19} \mathrm{~F}$ NMR $(282 \mathrm{MHz}$, $\left.\mathrm{CDCl}_{3}\right): \delta-46.4$ (s, 2F). IR (film) $/ \mathrm{cm}^{-1}: 3126,2923,2851$, 1574, 1538, 1426, 1329, 1195, 1119, 1072, 964, 789. HRMS (ESI-TOF) $m / z$ : calcd for $\mathrm{C}_{13} \mathrm{H}_{9} \mathrm{BrF}_{2} \mathrm{~N}_{3} \mathrm{~S}[\mathrm{M}+\mathrm{H}]^{+}$, 355.9669; found, 355.9663 .

$N$-(Benzo[d][1,3]dioxol-5-yl)-4-(bromodifluoromethyl)thiazol-2-yl-amine (6I). Orange oil (104 mg, 77\%). $R_{\mathrm{f}} 0.6$ (30\% EtOAc/ $n$-hexane). ${ }^{1} \mathrm{H}$ NMR $\left(700 \mathrm{MHz} \mathrm{CDCl}_{3}\right): \delta 7.38$ (br s, $1 \mathrm{H}, \mathrm{NH}), 6.90-6.87(\mathrm{~m}, 2 \mathrm{H}, 1 \times \mathrm{Ar}-\mathrm{H}$ overlapping $1 \times$ HetAr-H), 6.81 (d, $J=8.2 \mathrm{~Hz}, 1 \mathrm{H}, \mathrm{Ar}-\mathrm{H}), 6.79-6.76(\mathrm{~m}, 1 \mathrm{H}$, $\mathrm{Ar}-\mathrm{H}), 6.01$ (s, $\left.2 \mathrm{H}, \mathrm{O}-\mathrm{CH}_{2}-\mathrm{O}\right) .{ }^{13} \mathrm{C} \mathrm{NMR}(126 \mathrm{MHz}$, $\left.\mathrm{CDCl}_{3}\right): \delta 168.5(\mathrm{C}=\mathrm{N}), 148.7(\mathrm{Ar}-\mathrm{Cq}), 146.9\left(\mathrm{t},{ }^{2} J_{(\mathrm{C}-\mathrm{F})}=\right.$ $28.4 \mathrm{~Hz}, \mathrm{Ar}-\mathrm{Cq}$ ), 145.6 (Ar-Cq), 133.8 (Ar-Cq), 115.1 (Ar-C), $114.1\left(\mathrm{t},{ }^{1} J_{(\mathrm{C}-\mathrm{F})}=300.1 \mathrm{~Hz}, \mathrm{CF}_{2} \mathrm{Br}\right), 108.9(\mathrm{Ar}-\mathrm{C}), 106.6(\mathrm{t}$, $\left.{ }^{3} J_{(\mathrm{C}-\mathrm{F})}=4.8 \mathrm{~Hz}, \mathrm{Ar}-\mathrm{C}\right), 103.9$ (Ar-C), $101.8\left(\mathrm{O}-\mathrm{CH}_{2}-\mathrm{O}\right)$. ${ }^{19} \mathrm{~F}$ NMR (282 MHz, $\mathrm{CDCl}_{3}$ ): $\delta-46.6(2 \mathrm{~F})$. IR (film) $/ \mathrm{cm}^{-1}$ : 3418, 2091, 1634, 1505, 1488, 1451, 1238, 1188, 1123, 1071, 1038, 968. HRMS (ESI-TOF) $\mathrm{m} / z$ : calcd for $\mathrm{C}_{11} \mathrm{H}_{6} \mathrm{BrF}_{2} \mathrm{~N}_{2} \mathrm{O}_{2} \mathrm{~S}[\mathrm{M}-\mathrm{H}]^{-}$, 346.9301; found, 346.9306 .

2-[4-((4-(Bromodifluoromethyl)thiazol-2-yl)amino)phenyl]propanoic Acid (Br-DF2755Y). Yellow solid (683 mg, $60 \%) . R_{\mathrm{f}} 0.6$ (30\% n-hexane/EtOAc). ${ }^{1} \mathrm{H}$ NMR (500 MHz, CD3CN): $\delta 8.55$ (br s, $1 \mathrm{H}, \mathrm{NH}), 7.51$ (d, $J=8.5 \mathrm{~Hz}, 2 \mathrm{H}, \mathrm{Ar}-$ $\mathrm{H}), 7.30$ (d, $J=8.5 \mathrm{~Hz}, 2 \mathrm{H}, \mathrm{Ar}-\mathrm{H}), 7.15$ (s, 1H, HetAr-H), $3.70(\mathrm{q}, J=7.2 \mathrm{~Hz}, 1 \mathrm{H}, \mathrm{CH}), 1.42\left(\mathrm{~d}, J=7.2 \mathrm{~Hz}, 3 \mathrm{H}, \mathrm{CH}_{3}\right)$. ${ }^{13} \mathrm{C}$ NMR (126 MHz, $\left.\mathrm{CD}_{3} \mathrm{CN}\right): \delta 176.0(\mathrm{C}=\mathrm{O}), 166.3(\mathrm{C}=$ $\mathrm{N}), 146.8\left(\mathrm{t},{ }^{2} J_{(\mathrm{C}-\mathrm{F})}=28.2 \mathrm{~Hz}, \mathrm{Ar}-\mathrm{Cq}\right), 140.2(\mathrm{Ar}-\mathrm{Cq}), 136.6$ (Ar-Cq), 129.2 ( $2 \times$ Ar-C), 119.3 (2 $\times$ Ar-C), $115.4\left(\mathrm{t},{ }^{1} J_{(\mathrm{C}-\mathrm{F})}\right.$ $\left.=297.9 \mathrm{~Hz}, \mathrm{CF}_{2} \mathrm{Br}\right), 109.0\left(\mathrm{t},{ }^{3} J_{(\mathrm{C}-\mathrm{F})}=4.9 \mathrm{~Hz}, \mathrm{Ar}-\mathrm{C}\right), 45.1$ $(\mathrm{CH}), 18.7\left(\mathrm{CH}_{3}\right) .{ }^{19} \mathrm{~F}$ NMR $\left(470 \mathrm{MHz}, \mathrm{CDCl}_{3}\right): \delta-51.3$ (2F). HRMS (ESI-TOF) $m / z$ : calcd for $\mathrm{C}_{13} \mathrm{H}_{10} \mathrm{BrF}_{2} \mathrm{~N}_{2} \mathrm{O}_{2} \mathrm{~S}[\mathrm{M}$ $-\mathrm{H}^{-}$, 374.9614; found, 374.9631 .

Procedure for the Synthesis of 4 (bromodifluoromethyl)thiazol-2-amine (8). To a solution of thiourea $(30 \mathrm{mg}, 0.39 \mathrm{mmol})$ in dry acetonitrile $(500 \mu \mathrm{L})$ in a sealed tube, 1,3-dibromo-1,1-difluoropropan-2-one (3a) (100 $\mathrm{mg}, 0.39 \mathrm{mmol}$ ) was added dropwise, and the mixture was heated to $80{ }^{\circ} \mathrm{C}$ for $3 \mathrm{~h}$. The reaction crude was diluted with ethyl acetate $(3 \mathrm{~mL})$ and washed with hexane. The organic phase was filtered and the solvent was removed under reduced pressure to afford thiazole 8 as a yellow solid (complete conversion). $R_{\mathrm{f}} 0.8$ (30\% EtOAc/n-hexane). ${ }^{1} \mathrm{H}$ NMR (700 $\left.\mathrm{MHz} \mathrm{CDCl}_{3}\right): \delta 6.88(\mathrm{~s}, 1 \mathrm{H}, \mathrm{HetAr}-\mathrm{H}), 5.18$ (br s, $\left.2 \mathrm{H}, \mathrm{NH}_{2}\right)$. ${ }^{13} \mathrm{C}$ NMR $\left(176 \mathrm{MHz}, \mathrm{CDCl}_{3}\right): \delta 168.3(\mathrm{C}=\mathrm{N}), 146.7(\mathrm{t}$, $\left.{ }^{2} J_{(\mathrm{C}-\mathrm{F})}=28.3 \mathrm{~Hz}, \mathrm{Ar}-\mathrm{C}_{\mathrm{q}}\right), 114.0\left(\mathrm{t},{ }^{1} J_{(\mathrm{C}-\mathrm{F})}=299.6 \mathrm{~Hz}, \mathrm{CF}_{2} \mathrm{Br}\right)$, $108.1\left(\mathrm{t},{ }^{3} J_{(\mathrm{C}-\mathrm{F})}=4.9 \mathrm{~Hz}\right.$, Ar-C). ${ }^{19} \mathrm{~F} \mathrm{NMR}(282 \mathrm{MHz}$, $\mathrm{CDCl}_{3}$ ): $\delta-46.5$ (2F). IR (film) $/ \mathrm{cm}^{-1}: 3290,3121,2925$, $1722,1633,1548,1471,1286,1196,1122,1072$, 963. HRMS (ESI-TOF) $m / z$ : calcd for $\mathrm{C}_{4} \mathrm{H}_{4} \mathrm{BrF}_{2} \mathrm{~N}_{2} \mathrm{~S}[\mathrm{M}+\mathrm{H}]^{+}, 228.9241$; found, 228.9251.

General Procedure for Br/F Exchange Reactions. Procedure A for conversion of $\mathbf{8}$ to $\mathbf{9}$ is reported. To a solution of $8(25 \mathrm{mg}, 0.11 \mathrm{mmol})$ in acetonitrile $(500 \mu \mathrm{L})$ in a sealed tube, silver triflate $(28 \mathrm{mg}, 0.11 \mathrm{mmol})$, potassium fluoride (13 mg, $0.22 \mathrm{mmol}$ ), and Kriptofix ( $83 \mathrm{mg}, 0.22$ $\mathrm{mmol}$ ) were consecutively added, and the mixture was stirred at room temperature until TLC or ${ }^{19} \mathrm{~F}$ NMR sampling revealed the full conversion. The crude was diluted with ethyl acetate (3 $\mathrm{mL})$ and washed with water $(3 \times 3 \mathrm{~mL})$. The organic phase was dried over sodium sulfate and the solvent was removed under vacuum. Filtration on a pad of silica provided the analytically pure product. Procedure B was used for conversion of Br-DF2755 to DF2755Y. To a solution of potassium fluoride $(58 \mathrm{mg}, 1.00 \mathrm{mmol}$ ) and Kriptofix ( $83 \mathrm{mg}, 0.22$ $\mathrm{mmol})$ in dry DMF $(0.5 \mathrm{~mL})$ at $80{ }^{\circ} \mathrm{C}$ in a sealed tube, $\mathrm{Br}$ DF2755 (25 mg, $0.11 \mathrm{mmol})$ in $0.5 \mathrm{~mL}$ of dry DMF was added dropwise. The mixture was stirred at $80{ }^{\circ} \mathrm{C}$ for $5 \mathrm{~min}$, cooled at room temperature, and $2 \mathrm{~mL}$ of a $1 \mathrm{M}$ aqueous solution of $\mathrm{HCl}$ were added. The crude was extracted with ethyl acetate $(3 \times 3 \mathrm{~mL})$, the organic phase was dried over sodium sulfate, and the solvent was removed under vacuum. Treatment with $\mathrm{CH}_{2} \mathrm{Cl}_{2}(2 \mathrm{~mL})$ led to the precipitation of DF2755Y in an analytically pure form.

4-(Trifluoromethyl)-2-aminothiazole (9). Isolated as orange oil (17 $\mathrm{mg}, 90 \%)$ following the general procedure, full conversion was observed after stirring at room temperature for 16 h. ${ }^{19} \mathrm{~F} \mathrm{NMR}\left(470 \mathrm{MHz}, \mathrm{CDCl}_{3}\right): \delta-64.8$ (3F). ${ }^{1} \mathrm{H}$ NMR $\left(500 \mathrm{MHz}, \mathrm{CDCl}_{3}\right): \delta 6.90(\mathrm{~s}, 1 \mathrm{H}), 6.00($ br s, $2 \mathrm{H})$. Data are consistent with literature. ${ }^{24}$

[4-(Trifluoromethyl)-1,3-thiazol-2-yl](p-tolyl)amine (7a). Isolated as yellow oil (9 $\mathrm{mg}, 92 \%)$ following the general procedure, full conversion was observed after stirring at room temperature for $5 \mathrm{~min} .{ }^{1} \mathrm{H}$ NMR $\left(700 \mathrm{MHz}, \mathrm{CDCl}_{3}\right): \delta 7.40$ (br s, 1H, NH), 7.23-7.16 (m, 4H, Ar-H), 7.00 (s, 1H, HetAr$\mathrm{H}), 2.35\left(\mathrm{~s}, 3 \mathrm{H}, \mathrm{CH}_{3}\right) .{ }^{13} \mathrm{C} \mathrm{NMR}\left(176 \mathrm{MHz} \mathrm{CDCl}_{3}\right): \delta 167.9$ $(\mathrm{C}=\mathrm{N}), 140.9\left(\mathrm{q},{ }^{2} \mathrm{~J}_{(\mathrm{C}-\mathrm{F})}=37.0 \mathrm{~Hz}, \operatorname{Ar}-\mathrm{C}_{\mathrm{q}}\right), 137.1\left(\operatorname{Ar}-\mathrm{C}_{\mathrm{q}}\right)$, 
$134.7\left(\mathrm{Ar}_{-} \mathrm{C}_{\mathrm{q}}\right), 130.4(2 \times \mathrm{Ar}-\mathrm{C}), 120.5\left(\mathrm{q},{ }^{1} J_{(\mathrm{C}-\mathrm{F})}=269.9 \mathrm{~Hz}\right.$, $\left.\mathrm{CF}_{3}\right), 120.2(2 \times \mathrm{Ar}-\mathrm{C}), 109.0\left(\mathrm{q},{ }^{3} J_{(\mathrm{C}-\mathrm{F})}=4.6 \mathrm{~Hz}, \mathrm{Ar}-\mathrm{C}\right), 21.0$ $\left(\mathrm{CH}_{3}\right) .{ }^{19} \mathrm{~F} \mathrm{NMR}\left(282 \mathrm{MHz}, \mathrm{CDCl}_{3}\right): \delta-65.1(3 \mathrm{~F})$. IR (film)/ $\mathrm{cm}^{-1}, 3196,2924,2854,1600,1552,1514,1375,1231,1166$, 1132 , 1079, 931. HRMS (ESI-TOF) $\mathrm{m} / z$ : calcd for $\mathrm{C}_{11} \mathrm{H}_{8} \mathrm{~F}_{3} \mathrm{~N}_{2} \mathrm{~S}[\mathrm{M}-\mathrm{H}]^{-}$, 257.0360; found, 257.0366.

N-(4-(Hexyloxy)phenyl)-4-(trifluoromethyl)thiazol-2amine (7j). Isolated as brown oil (19 $\mathrm{mg}, 87 \%)$ following the general procedure, full conversion was observed after stirring at room temperature for $15 \mathrm{~min} .{ }^{1} \mathrm{H} \mathrm{NMR}\left(500 \mathrm{MHz}, \mathrm{CDCl}_{3}\right): \delta$ 7.43 (br s, $1 \mathrm{H}, \mathrm{NH}), 7.23$ (d, $J=8.9 \mathrm{~Hz}, 2 \mathrm{H}, \mathrm{Ar}-H), 6.94(\mathrm{~s}$, 1H, HetAr- $H$ ), 6.92 (d, $J=8.9 \mathrm{~Hz}, 2 \mathrm{H}, \mathrm{Ar}-H), 3.96(\mathrm{t}, J=6.6$ $\left.\mathrm{Hz}, 2 \mathrm{H}, \mathrm{O}-\mathrm{CH}_{2}\right), 1.82-1.75\left(\mathrm{~m}, 2 \mathrm{H}, \mathrm{CH}_{2}\right), 1.50-1.43(\mathrm{~m}$, $\left.2 \mathrm{H}, \mathrm{CH}_{2}\right), 1.37-1.32\left(\mathrm{~m}, 4 \mathrm{H}, 2 \times \mathrm{CH}_{2}\right), 0.91(\mathrm{t}, J=6.9 \mathrm{~Hz}$, $\left.3 \mathrm{H}, \mathrm{CH}_{3}\right) .{ }^{13} \mathrm{C} \mathrm{NMR}\left(126 \mathrm{MHz} \mathrm{CDCl}_{3}\right): \delta 169.7(\mathrm{C}=\mathrm{N})$, $157.3\left(\mathrm{Ar}-\mathrm{C}_{\mathrm{q}}\right), 140.9\left(\mathrm{q},{ }^{2} J_{(\mathrm{C}-\mathrm{F})}=37.0 \mathrm{~Hz}, \mathrm{Ar}-\mathrm{C}_{\mathrm{q}}\right), 132.5(\mathrm{Ar}-$ $\left.C_{\mathrm{q}}\right), 123.8(2 \times \mathrm{Ar}-\mathrm{C}), 120.5\left(\mathrm{q},{ }^{1} J_{(\mathrm{C}-\mathrm{F})}=269.9 \mathrm{~Hz}, \mathrm{CF}_{3}\right)$, $115.7(2 \times \mathrm{Ar}-\mathrm{C}), 108.8\left(\mathrm{q},{ }^{3} \mathrm{~J}_{(\mathrm{C}-\mathrm{F})}=4.0 \mathrm{~Hz}, \mathrm{Ar}-\mathrm{C}\right), 68.5(\mathrm{O}-$ $\left.\mathrm{CH}_{2}\right), 31.7\left(\mathrm{CH}_{2}\right), 29.4\left(\mathrm{CH}_{2}\right), 25.9\left(\mathrm{CH}_{2}\right), 22.8\left(\mathrm{CH}_{2}\right), 14.2$ $\left(\mathrm{CH}_{3}\right) .{ }^{19} \mathrm{~F}$ NMR $\left(470 \mathrm{MHz}, \mathrm{CDCl}_{3}\right): \delta-65.2$ (3F). IR (film) $/ \mathrm{cm}^{-1}: 3407,3205,2951,1596,1568,1513,1248,1175$, $1163,1133,1024,737$. HRMS (ESI-TOF) $\mathrm{m} / z$ : calcd for $\mathrm{C}_{16} \mathrm{H}_{18} \mathrm{~F}_{3} \mathrm{~N}_{2} \mathrm{OS}[\mathrm{M}-\mathrm{H}]^{-}$, 343.1092; found, 343.1096.

(S)-2-(4-((4-(Trifluoromethyl)thiazol-2-yl)amino)phenyl)propanoic Acid (DF2755Y). Isolated as white solid (10 mg, $85 \%)$ following the general procedure, full conversion was observed after stirring at $80{ }^{\circ} \mathrm{C}$ for $20 \mathrm{~min}$. $[\alpha]_{\mathrm{D}}^{27}\left(c 1, \mathrm{CHCl}_{3}\right)$. ${ }^{1} \mathrm{H} \mathrm{NMR} \mathrm{(500} \mathrm{MHz,} \mathrm{CDCl}_{3}$ ): $\delta 9.25$ (br s, $\left.1 \mathrm{H}, \mathrm{NH}\right), 7.40(\mathrm{~d}$, $2 \mathrm{H}, J=7 \mathrm{~Hz}), 7.25(\mathrm{~d}, 2 \mathrm{H}, J=7 \mathrm{~Hz}), 7.00(\mathrm{~s}, 1 \mathrm{H}), 3.80(\mathrm{q}$, $1 \mathrm{H}, J=7 \mathrm{~Hz}), 1.55(\mathrm{~d}, 3 \mathrm{H}, J=7 \mathrm{~Hz}) .{ }^{19} \mathrm{~F}$ NMR $(282 \mathrm{MHz}$, acetone- $D_{6}$ ): $\delta-65.6(3 \mathrm{~F})$. HRMS (ESI-TOF) $\mathrm{m} / z$ : calcd for $\mathrm{C}_{13} \mathrm{H}_{10} \mathrm{~F}_{3} \mathrm{~N}_{2} \mathrm{O}_{2} \mathrm{~S}[\mathrm{M}-\mathrm{H}]^{-}$, 315.0415; found, 315.0449. Data are consistent with those reported into the literature. ${ }^{25}$

\section{ASSOCIATED CONTENT}

\section{S Supporting Information}

The Supporting Information is available free of charge on the ACS Publications website at DOI: 10.1021/acsomega.8b02273.

Characterization of new compounds $\left({ }^{1} \mathrm{H},{ }^{13} \mathrm{C}\right.$, and ${ }^{19} \mathrm{~F}$ NMR spectra) (PDF)

\section{AUTHOR INFORMATION}

\section{Corresponding Authors}

*E-mail: andrea.aramini@dompe.com (A.A.).

*E-mail: leonardo.degennaro@uniba.it (L.D.).

*E-mail: renzo.luisi@uniba.it (R.L.).

\section{ORCID}

Leonardo Degennaro: 0000-0002-2187-9419

Renzo Luisi: 0000-0002-9882-7908

\section{Notes}

The authors declare no competing financial interest.

\section{ACKNOWLEDGMENTS}

This research was supported by the project Laboratorio Sistema code PONa300369 financed by MIUR, MISE, Horizon 2020-PON 2014/2020 FARMIDIAB "code 338"; the University of Bari. We are grateful to Federica Ruta for the precious contribution in the preparation of some compounds studied in this work.

\section{REFERENCES}

(1) (a) Wang, J.; Sánchez-Roselló, M.; Aceña, J. L.; del Pozo, C.; Sorochinsky, A. E.; Fustero, S.; Soloshonok, V. A.; Liu, H. Fluorine in Pharmaceutical Industry: Fluorine-Containing Drugs Introduced to the Market in the Last Decade (2001-2011). Chem. Rev. 2014, 114, 2432-2506. (b) Fluorine in Pharmaceutical and Medicinal Chemistry: From Biophysical Aspects to Clinical Applications; Gouverneur, V., Müller, K., Eds.; Molecular Medicine and Medicinal Chemistry; Imperial College Press: London, 2012; Vol. 6.

(2) (a) Theodoridis, G. Fluorine-Containing Agrochemicals. An Overview of Recent Developments in Fluorine and the Environment: Agrochemicals, Archaeology, Green Chemistry and Water, 1st ed.; Tressaud, A., Ed.; Elsevier Science, 2006; Vol. 2. (b) Jeschke, P. The Unique Role of Fluorine in the Design of Active Ingredients for Modern Crop Protection. ChemBioChem 2004, 5, 570-589.

(3) (a) Hiyama, T.; Kanie, K.; Kasumoto, T.; Morizawa, Y.; Shimizu, M. Organofluorine Compounds: Chemistry and Applications; Yamamoto, H., Ed.; Springer: Berlin, 2000; p 1. (b) Kirsch, P. Modern Fluoroorganic Chemistry: Synthesis, Reactivity, Applications; Wiley-VCH: Weinheim, 2013.

(4) (a) Liang, T.; Neumann, C. N.; Ritter, T. Introduction of Fluorine and Fluorine-Containing Functional Groups. Angew. Chem., Int. Ed. 2013, 52, 8214-8264. (b) Merino, E.; Nevado, C. Addition of CF3 across unsaturated moieties: a powerful functionalization tool. Chem. Soc. Rev. 2014, 43, 6598-6608. (c) Shao, X.; Xu, C.; Lu, L.; Shen, Q. Shelf-Stable Electrophilic Reagents for Trifluoromethylthiolation. Acc. Chem. Res. 2015, 48, 1227-1236. (d) Charpentier, J.; Früh, N.; Togni, A. Electrophilic Trifluoromethylation by Use of Hypervalent Iodine Reagents. Chem. Rev. 2015, 115, 650-682. (e) Liu, X.; Xu, C.; Wang, M.; Liu, Q. Trifluoromethyltrimethylsilane: Nucleophilic Trifluoromethylation and Beyond. Chem. Rev. 2015, 115, 683-730. (f) Alonso, C.; Martínez de Marigorta, E.; Rubiales, G.; Palacios, F. Carbon Trifluoromethylation Reactions of Hydrocarbon Derivatives and Heteroarenes. Chem. Rev. 2015, 115, 18471935. (g) Egami, H.; Sodeoka, M. Trifluoromethylation of Alkenes with Concomitant Introduction of Additional Functional Groups. Angew. Chem., Int. Ed. 2014, 53, 8294-8308.

(5) (a) Prakash, G. K. S.; Hu, J. New Nucleophilic Fluoroalkylation Chemistry. In Fluorinated Synthons; Soloshonok, V. A., Ed.; ACS Symposium Series No. 911; American Chemical Society: Washington, DC, 2005. (b) Chen, B.; Vicic, D. A. Transition-Metal-Catalyzed Difluoromethylation, Difluoromethylenation, and Polydifluoromethylenation Reactions. Organometallic Fluorine Chemistry; TopicsinOrganometallic Chemistry 52; Springer-Verlag Berlin Heidelberg, 2014.

(6) Prakash, G. K. S.; Wang, Y.; Hu, J.; Olah, G. A. Nucleophilic difluoromethylation and difluoromethylenation using bromodifluoromethyl phenyl sulfone. J. Fluorine Chem. 2005, 126, 1361-1367.

(7) (a) Kitazume, T.; Kamazaki, T. Experimental Methods in Organic Fluorine Chemistry; Gordon and Breach Science: Tokyo, 1998. (b) Blackburn, G. M.; Kent, D. E.; Kolkmann, F. The synthesis and metal binding characteristics of novel, isopolar phosphonate analogues of nucleotides. J. Chem. Soc., Perkin Trans. 1 1984, 1119-1125.

(8) Góme, A. B.; Cortés González, M. A.; Lübcke, M.; Johansson, M. J.; Schou, M.; Szabó, K. J. Synthesis of trifluoromethyl moieties by late-stage copper (I) mediated Nucleophilic fluorination. J. Fluorine Chem. 2017, 194, 51-57.

(9) For some representative halex-exchange processes toward $\left[{ }^{18} \mathrm{~F}\right]$ $\mathrm{CF}_{3}$, see: (a) Suehiro, M.; Yang, G.; Torchon, G.; Ackerstaff, E.; Humm, J.; Koutcher, J.; Ouerfelli, O. Radiosynthesis of the tumor hypoxia marker $[18 \mathrm{~F}]$ TFMISO via O-[18F]trifluoroethylation reveals a striking difference between trifluoroethyl tosylate and iodide in regiochemical reactivity toward oxygen nucleophiles. Bioorg. Med. Chem. 2011, 19, 2287-2297. (b) Huiban, M.; Tredwell, M.; Mizuta, S.; Wan, Z.; Zhang, X.; Collier, T. L.; Gouverneur, V.; Passchier, J. A broadly applicable $[18 \mathrm{~F}]$ trifluoromethylation of aryl and heteroaryl iodides for PET imaging. Nat. Chem. 2013, 5, 941-944, and references therein .

(10) (a) Neumann, C. N.; Ritter, T. Late-stage fluorination: fancy novelty or useful tool? Angew. Chem., Int. Ed. 2015, 54, 3216-3221. 
(b) Chansaenpak, K.; Vabre, B.; Gabbaï, F. P. [18F]-Group 13 fluoride derivatives as radiotracers for positron emission tomography. Chem. Soc. Rev. 2016, 45, 954-971. (c) Prabhakaran, J.; Underwood, M. D.; Parsey, R. V.; Arango, V.; Majo, V. J.; Simpson, N. R.; Van Heertum, R.; Mann, J. J.; Kumar, J. S. D. Synthesis and in vivo evaluation of [18F]-4-[5-(4-methylphenyl)-3-(trifluoromethyl)-1Hpyrazol-1-yl] benzenesulfonamide as a PET imaging probe for COX2 expression. Bioorg. Med. Chem. 2007, 15, 1802-1807. (d) Brooks, A. F.; Topczewski, J. J.; Ichiishi, N.; Sanford, M. S.; Scott, P. J. H. Late-stage $[18 \mathrm{~F}]$ fluorination: new solutions to old problems. Chem. Sci. 2014, 5, 4545-4553.

(11) Stachulski, A. V.; Santoro, M. G.; Piacentini, S.; Belardo, G.; Frazia, S. L.; Pidathala, C.; Row, E. C.; Berry, N. G.; Iqbal, M.; Allman, S. A.; Semple, J. E.; Eklov, B. M.; O’Neill, P. M.; Rossignol, J.F. Second-generation nitazoxanide derivatives: thiazolides are effective inhibitors of the influenza A virus. Future Med. Chem. 2018, 10, 851862.

(12) (a) Dornelles, F. N.; Andrade, E. L.; Campos, M. M.; Calixto, J. B. Role of CXCR2 and TRPV1 in functional, inflammatory and behavioural changes in the rat model of cyclophosphamide-induced haemorrhagic cystitis. Br. J. Pharmacol. 2014, 171, 452-467. (b) Shadidi, K. R. New Drug Targets in Rheumatoid Arthritis. BioDrugs 2004, 18, 181-187. (c) Owen, C. Chemokine Receptors in Airway Disease: which Receptors to Target? Pulm. Pharmacol. Ther. 2001, 14, 193-202. (d) Stellato, C.; Brummet, M. E.; Plitt, J. R.; Shahabuddin, S.; Baroody, F. M.; Liu, M. C.; Ponath, P. D.; Beck, L. A. Cutting Edge: Expression of the C-C Chemokine Receptor CCR3 in Human Airway Epithelial Cells. J. Immunol. 2001, 166, 1457-1461.

(13) Lopes, A. H.; Brandolini, L.; Aramini, A.; Bianchini, G.; Silva, R. L.; Zaperlon, A. C.; Verri, W. A., Jr.; Alves-Filho, J. C.; Cunha, F. Q.; Teixeira, M. M.; Allegretti, M.; Cunha, T. M. DF2755A, a novel non-competitive allosteric inhibitor of CXCR $1 / 2$, reduces inflammatory and post-operative pain. Pharmacol. Res. 2016, 103, 69-79.

(14) (a) Zhang, C.-P.; Cao, H.-P.; Wang, Z.-L.; Zhang, C.-T.; Chen, Q.-Y.; Xiao, J.-C. New Electrophilic Bromodifluoromethylation and Pentafluoroethylation Reagents. Synlett 2010, 1089-1092. (b) Urban, C.; Macé, Y.; Cadoret, F.; Blazejewski, J.-C.; Magnier, E. Divergent Preparation of Fluoroalkylated Sulfilimine and Sulfilimino Iminium Salts. Adv. Synth. Catal. 2010, 352, 2805-2814. (c) Urban, C.; Cadoret, F.; Blazejewski, J.-C.; Magnier, E. Sulfoximines as a Versatile Scaffold for Electrophilic Fluoroalkylating Reagents. Eur. J. Org. Chem. 2011, 4862-4867. (d) Liu, G.; Mori, S.; Wang, X.; Noritake, S.; Tokunaga, E.; Shibata, N. Efficient synthesis of unsymmetrical S(bromodifluoromethyl)diarylsulfonium salts for electrophilic bromodifluoromethylating reagents. New J. Chem. 2012, 36, 1769-1773. (e) Shiosaki, M.; Inoue, M. Bromodifluoromethylation of aromatic Grignard reagents with CF2Br2. Tetrahedron Lett. 2014, 55, 68396843.

(15) Zhang, J.; Xu, X.-H.; Qing, F.-L. Bromodifluoromethylation of heteroaromatics with sodium bromodifluoromethanesulfinate. Tetrahedron Lett. 2016, 57, 2462-2464.

(16) Ge, F.; Wang, Z.; Wan, W.; Lu, W.; Hao, J. One-pot synthesis of 2-trifluoromethyl and 2-difluoromethyl substituted benzo-1,3diazoles. Tetrahedron Lett. 2007, 48, 3251-3254.

(17) (a) Burkholder, C.; Dolbier, W. R., Jr.; Médebielle, M. Syntheses of 2-(Bromodifluoromethyl)benzoxazole and 5-(Bromodifluoromethyl)-1,2,4-oxadiazoles". J. Fluorine Chem. 1999, 95, 127130. (b) Boyer, J.; Arnoult, E.; Médebielle, M.; Guillemont, J.; Unge, J.; Jochmans, D. Difluoromethylbenzoxazole pyrimidine thioether derivatives: a novel class of potent non-nucleoside HIV-1 reverse transcriptase inhibitors. J. Med. Chem. 2011, 54, 7974-7985. (c) Jiang, H.; Sun, L.; Yuan, S.; Lu, W.; Wan, W.; Zhu, S.; Hao, J. A facile one-pot synthesis of 2-fluoroalkyl 1,3-imidazolines and 1,3oxazolines through imidoyl halide intermediates. Tetrahedron 2012, 68, 2858-2863. (d) Jiang, H.; Yan, L.; Xu, M.; Lu, W.; Cai, Y.; Wan, W.; Yao, J.; Wu, S.; Zhu, S.; Hao, J. Nucleophile-Dependent Regioselective Reaction of (S)-4-Benzyl-2-Fluoroalkyl-1,3-Oxazolines. J. Org. Chem. 2013, 78, 4261-4269.
(18) Ghodse, S. M.; Telvekar, V. N. Synthesis of 2-aminothiazole derivatives from easily available thiourea and alkyl/aryl ketones using aqueous $\mathrm{NaICl}$. Tetrahedron Lett. 2015, 56, 472-474.

(19) South, M. S.; Van Sant, K. A. Reactions of a 4(trifluoromethyl)thiazole dianion. J. Heterocycl. Chem. 1991, 28, 1017-1024.

(20) A very recent review highlights the importance of difluoroketones in synthesis: Pattison, G. Methods for the Synthesis of $\alpha, \alpha$-Difluoroketones. Eur. J. Org. Chem. 2018, 3520-3540.

(21) (a) Parisi, G.; Colella, M.; Monticelli, S.; Romanazzi, G.; Holzer, W.; Langer, T.; Degennaro, L.; Pace, V.; Luisi, R. Exploiting a "Beast" in Carbenoid Chemistry: Development of a Straightforward Direct Nucleophilic Fluoromethylation Strategy. J. Am. Chem. Soc. 2017, 139, 13648-13651. (b) Degennaro, L.; Fanelli, F.; Giovine, A.; Luisi, R. External trapping of halomethyllithium enabled by flow microreactors. Adv. Synth. Catal. 2014, 357, 21-27.

(22) (a) Esteban, S. G.; de la Cruz, P.; Aljarilla, A.; Arellano, L. M.; Langa, F. Panchromatic Push-Pull Chromophores based on Triphenylamine as Donors for Molecular Solar Cells. Org. Lett. 2011, 13, 5362-5365. (b) Aoyama, T.; Murata, S.; Arai, I.; Araki, N.; Takido, T.; Suzuki, Y.; Kodomari, M. One pot synthesis using supported reagents system $\mathrm{KSCN} / \mathrm{SiO} 2-\mathrm{RNH} 3 \mathrm{OAc} / \mathrm{Al} 2 \mathrm{O} 3$ : synthesis of 2-aminothiazoles and $\mathrm{N}$-allylthioureas. Tetrahedron 2006, 62, 3201-3213. (c) Rudolph, J. Facile Access to N-Thiazolyl $\alpha$ Amino Acids from $\alpha$-Bromo Ketones and $\alpha$-Amino Acids. Tetrahedron 2000, 56, 3161-3165. (d) Meshram, H. M.; Thakur, P. B.; Madhu Babu, B.; Bangade, V. M. Convenient and simple synthesis of 2aminothiazoles by the reaction of $\alpha$-halo ketone carbonyls with ammonium thiocyanate in the presence of $\mathrm{N}$-methylimidazole. Tetrahedron Lett. 2012, 53, 5265-5269. (e) Schantl, J. G.; Lagoja, I. M. Expedient Synthesis of N-Substituted 2-Aminothiazoles. Synth. Commun. 1998, 28, 1451-1462.

(23) Preshlock, S.; Tredwell, M.; Gouverneur, V. 18F-Labeling of Arenes and Heteroarenes for Applications in Positron Emission Tomography. Chem. Rev. 2016, 116, 719-766.

(24) Tanaka, K.; Nomura, K.; Oda, H.; Yoshida, S.; Mitsuhashi, K. Synthesis of trifluoromethylthiazoles and their application to azo dyes. J. Heterocycl. Chem. 1991, 28, 907-911.

(25) Allegretti, M.; Aramini, A.; Bianchini, G.; Cesta, M. C. 2-Arylpropionic acids and derivatives and pharmaceutical compositions containing them. EP2166006 A1, 2010. 